\title{
Evaluating the $\mathrm{COACH}$ Program for African Americans
}

\author{
with Type 2 Diabetes
}

\section{Dianna White FNP-BC, DNP student}

Master of Science, Hampton University, 1995

\author{
A Capstone Presented to the Graduate Faculty of the \\ University of Virginia In Candidacy for the Degree of \\ Doctor of Nursing Practice \\ School of Nursing \\ University of Virginia \\ April, 2015
}

Kathryn Reid, PhD, APRN,FNP-BC, chair

Signature of Chair

Ivora (Ivy) Hinton, $\mathrm{PhD}$

Signature of Member

Ishan Williams, $\mathrm{PhD}$

Signature of Member

Randy Jones, PhD, RN, FAAN

Signature of Member 


\section{Acknowledgement}

A resounding, thank you to Dr. Reid, my advisor and capstone committee chair, who has been exemplary in guiding my path through the capstone project. Although she juggles numerous demanding rolls within the school of nursing her dedication and commitment to see me through this process never waivered. For this, I am deeply grateful. To Dr. Hinton, thank you for your everlasting support and assistance with the data analysis on this project, your vision saw me through. Dr. Williams, thank you for your insightfulness regarding preparation. Lastly to Dr. Jones, thank you for joining my committee and providing your expertise. Since all committee members were invaluable to the success of this project, I want to thank my entire committee for your commitment and dedication towards education. I was truly blessed to have each of you on my team.

Lastly, I would be remised if I did not say a heart-felt thank you to my daughters, Taylor and Logan White, who have been my greatest supporters and loudest cheerleaders during this journey. Taylor, although you entered college while I pursue this endeavor, your continuous support and positive words of encouragement was invaluable. Logan, you missed numerous birthday party's and gatherings because mom was too busy with school work to attend, thanks for your unwavering support. I love you both enormously. 


\begin{abstract}
Purpose: To evaluate changes in knowledge, concerning diet and fasting blood sugars, of African American participants in a six-week $\mathrm{COACH}$ program.
\end{abstract}

Background: An epidemic of Type 2 Diabetes, primarily affecting minorities is emerging. This alarming and disheartening statistics must be addressed (CDC, 2011). The principle objective of this proposal was to evaluate the results of implementing the $\mathrm{COACH}$ program to increase knowledge regarding diet, and to improve glycemic control among African American adults. Study Design: A pre-experimental design evaluated knowledge change and fasting blood sugars related to the $\mathrm{COACH}$ program. The sample size included up to 10 African Americans with Type 2 Diabetes, age 21 or older.

Methods: An 11 item questionnaire and a pre-and post-fasting blood sugar values log was completed by all participants prior to starting the program and after completion of the six week $\mathrm{COACH}$ program. Statistical analysis consisted of the T-test (McNemar Chi-square test for nominal data) using the pre-and post-sets of scores for the same group. Key words: Type 2 Diabetes, African Americans, the COACH program 


\section{Table of Contents}

Section I

Introduction

Evidence of the Problem

Purpose of Project

8

Section II

Theoretical Framework

Review of Literature

Section III

Methods

15

Project Overview

Project Design

Protection of Human Subjects

Data Management

Data Analysis

Section IV

Findings

Section V

Discussion

Nursing Practice Implications

Strength and Weakness

Limitations

Future Research 


\section{Appendices}

Appendix A: Consent (Retrieved from IRB) 34

$\begin{array}{ll}\text { Appendix B: Welcome Letter } & 40\end{array}$

Appendix C: Demographic Questionnaire 41

Appendix D: Road to Health Pre-and Post-test 42

Appendix E: Pre-and Post-Fasting Blood Glucose 46

Appendix F: Telephone Checklist 47

Appendix G: Coach Evaluation $\quad 48$

Appendix H: Administrative Approval 49

Appendix I: Instructions for Authors: Clinical Diabetes Journal 50

$\begin{array}{ll}\text { Appendix J: Draft Manuscript } & 61\end{array}$ 


\author{
Evaluating the $\mathrm{COACH}$ program for African Americans \\ with Type 2 Diabetes
}

\title{
Section I
}

\section{Introduction}

Obesity is a major health issue, and is associated with other serious health problems such as hypertension, cardiovascular diseases, and Type 2 Diabetes Mellitus (Diabetes statistics, 2011). According Ogden and Flegal (2010), obesity is defined as having a body weight greater than or equal to $120 \%$ of desirable body weight. Unfortunately, obesity is, often, a conduit to Type 2 Diabetes.

More than one-third of U.S. adults (35.7\%) are obese. According to the Center for Disease Control and Prevention (CDC, 2013), a dramatic increase in obesity in the United States has occurred over the past 20 years. The average person in the U.S. is more than 24 pounds heavier than in the1980s (Ogden \& Flegal, 2010). This drastic change has propelled both the CDC and the U.S. Department of Human Health Services Office of Disease Prevention and Health Promotion to identify nutrition, physical activity and obesity as leading health determinants (CDC, 2013). Due to the drastic increase of obese individuals worldwide, the World Health Organization (2012) anticipates the incidence of Type 2 Diabetes to double over the next twenty years.

Adult African Americans are at 1.8 times greater risk of being overweight, developing diabetes, and suffering severe complications from the disease than non-Hispanic whites (American Diabetes Association (ADA), 2013). A potential reason for negative outcomes in African Americans diagnosed with Type 2 Diabetes is the lack of knowledge regarding the disease process, which may lead to poor glycemic control through lack of proper diet and 
exercise (McKenzie \& Shelley, 2010). Effective methods are needed for improving diabetes management for African Americans to assist in reducing health disparities within this population (ADA, 2013).

\section{Evidence of the Problem}

Although one in ten adults in the United States have diabetes now, as many as one in three are predicted to have diabetes by 2050 due to an older more diverse population (CDC, 2011). Currently, one out of every five dollars spent on health care in the United States is attributed to the care of someone with diabetes (ADA, 2013). The national health goals set by the United States in 2010 called for a reduction in both the economic and health burden related to diabetes; however, the disease seemingly continues, largely, to be unabated in the United States (CDC, 2011). Multiple studies have shown diabetic complications can be deterred by early diabetes management (CDC, 2011). However, despite numerous advances in technology, there remains a blurred line between recommended and actual diabetes best-care practices.

To determine whether a person has diabetes or pre-diabetes, health care providers have several options available, including an oral glucose tolerance test, a fasting plasma glucose test, and the hemoglobin A1C test. The oral glucose test checks the patient's serum blood glucose levels before, and 2 hours after, he/she ingests a sugary sweet drink. A normal oral glucose tolerance test result is less than $140 \mathrm{mg} / \mathrm{dl}$. Pre-diabetes is indicated by $140 \mathrm{mg} / \mathrm{dl}$ to $199 \mathrm{mg} / \mathrm{dl}$ result and a diabetes diagnosis is indicated by a yield of $200 \mathrm{mg} / \mathrm{dl}$ or higher. The normal levels of the fasting plasma glucose test (FPG) are less than $100 \mathrm{mg} / \mathrm{dl}$, pre-diabetes $100 \mathrm{mg} / \mathrm{dl}$ to $125 \mathrm{mg} / \mathrm{dl}$ and diabetes $126 \mathrm{mg} / \mathrm{dl}$ or higher. The hemoglobin A1C, a serum blood test, can also be used. If the $\mathrm{A} 1 \mathrm{C}$ is $5.7 \%$ or less, the client is not predisposed for Type 2 Diabetes; $5.7 \%$ to $6.4 \%$ indicates pre diabetes; and $6.5 \%$ or greater indicates Type 2 Diabetes (ADA, 2013). Any of these tests can be utilized to diagnose pre-diabetes or diabetes; however, the American Diabetes 
Association (ADA) recommends the FPG because it is quicker and cheaper than a serum blood test. Maintaining blood glucose levels below $100 \mathrm{mg} / \mathrm{dl}$ can prevent or delay many of the complications and costs associated with Type 2 Diabetes Mellitus.

Reducing the complications related to Type 2 Diabetes requires the patient to learn how to successfully self-manage the disease (Osborn, Cavanaugh, Wallison \& Rothman, 2010). Unfortunately, without sustained support, few people achieve their goals or master the tasks that will allow them to live healthy lives and inadvertently reduce their risk of costly complications and/or co-morbidities (Osborn et al., 2010). Healthcare providers have long recognized the need to provide culturally sensitive health education programs to enhance the health awareness among ethnic groups (ADA, 2011). Consequently, programs such as the Coaching people on Achieving Cardiovascular Health (COACH program), an evidence-based telephone coaching program, can be utilized to improve the health education of patients with chronic illnesses including Type 2 Diabetes (The COACH, 1995).

\section{Purpose of the Project}

The purpose of this project is to test the feasibility of the $\mathrm{COACH}$ program to influence the disease management knowledge of African Americans with Type 2 Diabetes. Specifically, this project will examine whether participants improve their scores on diabetes management knowledge, as well as demonstrate a decrease in fasting blood sugar levels after participating in the COACH program for six-weeks.

\section{Theoretical Framework}

The Social Cognitive Theory (Bandura, 1977) is used as the theoretical framework that informs this evaluation concerning the extent to which knowledge is gained through the $\mathrm{COACH}$ program among African-American adults with Type 2 Diabetes. Social Cognitive Theory stems from the social learning theory with a heavy emphasis on cognitive concepts (Bandura, 1977). 
Bandura's Social Cognitive Theory focuses on how children and adults operate cognitively in terms of their social experiences. According to Bandura, there are three main factors that influence behavior, and those factors can enhance behavior modifications of people with Type 2

Diabetes. These factors include:

1. Self-efficacy: confidence in one's ability to take action and overcome barriers;

2. Goals: knowledge and skill to perform a given behavior in relation to their own personal standards and effective self-reaction; and

3. Outcome expectancies: anticipated outcomes of a behavior individuals and communities adapt to behaviors that produce a positive outcome.

The $\mathrm{COACH}$ program interventions are expected to promote identification and increase awareness of self-management of diabetes symptoms, and encourage adoption of healthy behaviors to prevent complications or co-morbidities (Villanatos, Shaffer \& Gottlieb, 2002).

Although the Social Cognitive Theory is a grand theory, it provides a useful framework concerning the extent to which the $\mathrm{COACH}$ program will influence self-efficacy to modify or change diet and physical activity behaviors. The central emphasis of the Social Cognitive Theory is to understand and predict individual and group behaviors and to identify methods by which behavior can be modified or changed; it is frequently used to support interventions aimed at personality development, behavioral pathology, and health promotion (Bandura, 1977). 


\section{Section II}

\section{Review of the Literature}

A systematic review of relevant professional literature was conducted utilizing electronic databases including Ovid Medline, Pub Med, CINAHL, Cochrane and Google Scholar. Key search terms included "obesity", “type 2 diabetes", "the COACH program”, “African Americans" and a combination of these terms. The search was limited to the English language and the years 2004-2014 for Medline. No date limit was placed on the other databases. The initial search yielded 18,000 potential publications. A specific search including the terms: "COACH program and Nursing" narrowed the field to 50 additional publications. Excluded were non- English language publications. For the purpose of this project, only the studies addressing the $\mathrm{COACH}$ program, African Americans, Type 2 Diabetes, risk factors including socioeconomics, and lack of knowledge regarding risk for Type 2 Diabetes were selected yielding 28 articles.

\section{African Americans and Obesity}

According to the National Health Interview Survey (2012), approximately 13.2 million African Americans ages 20 and older were diagnosed with Type 2 Diabetes or were declared to be at risk for Type 2 Diabetes. A significant factor that places African Americans at risk is the definition that defines one as being obese or overweight: having a body mass greater than 25kg/m (Ogden \& Flegal, 2010). National population examinations have consistently reported an excess prevalence of obesity among African Americans, Latino Americans, and Native Americans as compared with non- Hispanic Whites (Chow, Foster, Gonzalez \& Melver, 2012). Although Type 2 Diabetes can occur in the absence of being overweight and obese, approximately 85 percent of people with Type 2 Diabetes are, indeed, overweight or obese (Zhang, Wang, \& Huang, 2009). 


\section{Socioeconomics-status and Type 2 Diabetes}

Socioeconomic status is commonly defined as a combination of education, income, and occupation, which generally determines one's access to health knowledge and health resources (Iceland \& Wilkes, 2006). In many parts of the United States, ethnicity is closely correlated with socioeconomic status. For example, African Americans are disproportionately overrepresented among those with lower socioeconomic status in both urban and rural parts of the United States (Iceland \& Wilkes, 2006).

Minorities of low socioeconomic status tend to also have less access to healthy foods and safe spaces for physical activity. It is well documented that the benefits of regular physical exercise include increased insulin sensitivity, increased glucose tolerance, increased mitochondrial function and increased muscle glucose uptake, decreases risk factors leading to obesity and Type 2 Diabetes. A sedentary lifestyle is the number one culprit that leads to obesity and Type 2 Diabetes (Balkau et al., 2008).

Research on food economics describes an inverse association between the cost of food and their energy density (Monsivais \& Drewnoski, 2007). For example, concentrated sugars, oils, and fats are the least expensive and more energy dense. In contrast, fresh vegetables, fruits, and whole grains are more expensive. Similarly, lean sources of protein such as fish, lean cuts of pork and beef typically cost more than their higher-fat counterparts. African Americans typically consume large amounts of sodium, fat and sugar with minimum amounts of fresh fruits, vegetables and whole grains (Monsivais \& Drewnoski, 2007). Diet is the pinnacle of managing diabetes, and poor dietary habits demonstrated by many African Americans put them at risk for having very poor glycemic control (CDC, 2008).

Within both urban and rural communities, African Americans live in areas that are considered "food deserts". Food deserts, as defined by Oxford (2010), are geographic areas in 
which access to affordable healthy food options are severely restricted or simply do not exist due to the lack of supermarkets within the transportation line. The United States Department of Agricultural (2010) reported that 2.2 Percent of all US households reside more than one mile away from a supermarket and the residents of that household do not own a car, and are therefore denied access to affordable and nutritious food. Researchers have identified a strong correlation between food insecurity an increase in diabetes rate (Chow, Foster, Gonzalez \& Melver, 2012).

\section{Lack of knowledge regarding management of type 2 diabetes}

Poor health outcomes among African American patients with Type 2 Diabetes can be explained by their lack of knowledge regarding the disease process and standard diabetes care, and poor communication with their healthcare providers. McKenzie \& Shelley (2010) reported that African Americans have a general knowledge deficit concerning Type 2 Diabetes, the risk factors of diabetes, and the prevention of the disease. Type 2 Diabetes is a multifactorial disease that is influenced by environmental, social, cultural and psychological factors, therefore healthcare providers must adequately address the barriers to Type 2 Diabetes self management and identify strategies to overcome such barriers (Kirkman et al., 1994).

\section{Utilizing the COACH program as a teaching method}

The COACH program was developed in Australia in 1995, and is an evidence-based coaching program centrally focused on the prevention of chronic diseases (The COACH program, 1995). It was developed to close the gap between the recommended treatment guidelines and the actual care that patients receive. The $\mathrm{COACH}$ program used the telephone to provide structured coaching to participants diagnosed with a chronic illness. This pragmatic intervention encouraged the patient to self-manage their disease by making relevant behavior changes, thus empowering them to play a greater role in their care with their providers (Ryn \& $\mathrm{Fu}, 2003)$. The $\mathrm{COACH}$ program leaders conducted telephone sessions with the participants to 
help them identify lifestyle issues, monitor their disease, encourage adherence to their medication regimen, and consult with their primary care provider and allied health services (The COACH program, 1995).

A plan of action was developed for each patient based on the national clinical guidelines for the specific disease process. Patients were provided targeted goals to achieve within the sixweek timeline. The timeline can be shorter, however, six-weeks was the recommended minimum, depending on the client's needs. Each session builds upon the previous task-oriented session. Patients received, on average, approximately six coaching sessions over the course of six-weeks, although additional coaching can be provided if warranted. During these sessions patients were educated about various appropriate lifestyles measures and behaviors (The COACH program, 1995).

Improving lifestyle behaviors through telephone COACHING has shown to be a cost effective approach to improving healthy lifestyle behaviors in a variety of conditions, including diabetes self-management (Schulze \& Hu, 2005). Telephone interventions may increase self-care adherence by developing tailored interventions that actively involve patients with individualized goals while subsequently addressing the barriers each patient faces. Patient education is also commonly recognized as an integral component of diabetes treatment. The COACH program's primary objective is to reduce the knowledge and treatment gap while motivating patients to assert appropriate lifestyle modifications and medical therapy (The COACH, 1995).

Although there are numerous techniques and strategies available to provide adequate education in problem-solving skills related to diabetes management, different educational programs produce different results in terms of the clinical cost-effectiveness (Odnoletkova et al., 2014). Due to the complexity of some interventions it is difficult to detect the direct effect of the patient education related to the actual outcomes. Patient education programs can be difficult to 
describe and difficult to reproduce in other settings. However, the COACH program is a wellestablished target driven telephone intervention that is cost effective to utilize and not complicated to implement (The COACH, 1995). 


\section{Section III}

\section{Methods}

\section{Project overview}

The purpose of this project was to implement a six-week telephone coaching program for African Americans with Type 2 Diabetes to evaluate the changes in knowledge concerning disease management with the projected outcomes of: (1) Improving scores on participants' diabetes knowledge comparing pre-test to post-test, and (2) observing a decrease in participant's fasting blood sugars after the six weeks COACH program. The telephone coach supported the participant in their lifestyle modifications to facilitate successful management of their daily routines. These routines include implementing appropriate self-care strategies, monitoring blood glucose, taking prescribed medications, and following diet and exercise regimens.

\section{Project design}

A pre-experimental study design (one group pre-post-test) with a convenient sample size was used. The purpose for selecting such a design was to examine whether the COACH program would be associated with the intended effect of increase knowledge regarding Type 2 Diabetes and improve fasting blood sugars with the project's participants. Data were collected on the participants' pre-and post-the intervention to access the participant's knowledge, and their fasting blood sugars following their participation in the six-weeks COACH program.

\section{Setting}

Participants were recruited from a community health center in Hampton Roads Virginia. It is conveniently located along the bus lines in an urban community to provide accessible health care. A broad range of services are provided for the adult patients including physical examinations for school and employment, management of diabetes and hypertension, treatment 
of numerous acute and chronic illnesses, and preventive services such as cancer screening, and family planning. The personnel hierarchy is as follows: the primary care physician and the nurse practitioner are responsible for delivering comprehensive community-oriented primary care to the 650 clients enrolled in at the community health center.

\section{Sample}

A convenience sample of ten volunteer African American men and women were recruited for this project who met the following inclusion criteria: African American; aged 21 or older; diagnosed with Type 2 Diabetes; currently receiving primary healthcare at the community health center; attended at least one standard ADA outpatient Diabetes Mellitus educational class; speaks English fluently; and are able to provide consent to participate in the $\mathrm{COACH}$ program.

Exclusion criteria included those who were: under age 21, non-English speakers, and had an active cancer diagnosis.

\section{Protection of Human Subjects}

Approval to implement this project was obtained from the University of Virginia Institutional Review Board for Health Sciences Research, protocol \# 17854. Participants were ensured that ethical principles were adhered to in this study, their information would be reported in aggregated form, and individual participants data would not be identifiable.

\section{Intervention}

The COACH program implemented in this study consisted of twelve calls from a coach, each lasting approximately 15 minutes per session. Calls were conducted twice per week over a six-week period. During each call the coach reinforced positive change. When program participants had difficulty achieving goals, the coach gently questioned them about obstacles and possible solutions. The coach was equipped with a telephone checklist to effectively conduct her calls. Medical advice was not provided during the coaching sessions. 


\section{Procedures}

After obtaining approval from the University of Virginia Institutional Review Board \#17854, providers at Norfolk Community Health Center informed their patients of the project and referred patients who wished to participate in the program to the coach. Once the patient agreed to participate in the project, he/she signed the consent form (Appendix A). Upon enrollment in the project, the participant received a letter to welcome him/her into the COACH program (Appendix B).

While participating in the $\mathrm{COACH}$ program, participants continued to receive their routine care from their primary care provider. A demographic questionnaire (Appendix C) was utilized to collect information and before the pre-test. Information collected included the following: age, education, income, residential locality in the Hampton Roads area, and the year the participant was diagnosed with Type 2 Diabetes. Each participant completed a baseline Type 2 Diabetes pre knowledge test (Appendix D) generated by the Road to Health program. The National Diabetes Educational Program in direct partnership with the National Institutes of Health and the Centers developed this knowledge test for disease and prevention (CDC, 2011).

A self-reported fasting blood sugar (finger-stick) test result was collected prior to the start of the COACHING program. Once the initial demographic, pre-knowledge test, and fasting blood sugars were collected, the telephone coaching documentation form was filed in each participant's chart. At that time the six-weeks telephone coaching program began. At the conclusion of the six-weeks telephone coaching program, diabetes knowledge and fasting blood sugar measurements were reassessed (Appendix E).

The $\mathrm{COACH}$ program includes twelve coaching telephone sessions that were implemented twice per week for each participant by the investigator (Appendix F). After the first week's sessions the participants and coach agreed upon the time for the calls --Monday and 
Tuesdays of the remainder weeks starting at 8:30 am. The phone calls lasted approximately 15 minutes per session and occurred over a six-week's period. The investigator/COACH was afforded the time at NCHC to conduct these biweekly calls prior to seeing scheduled patients in the office. Both the first and last sessions were slightly longer than 15 minutes each due to the time needed to administer pre-and post-knowledge test as well as to complete the COACH evaluation.

Participants in the program were often eager to provide details regarding their maintenance of their diet over the weekends. Often the discussion would lend itself to the participant's fasting blood sugars and the impact they perceived the $\mathrm{COACH}$ program was having on their improved fasting blood sugar even on the days the coach did not call. One participant reported he/she stayed on the prescribed diet because, "I knew I would have to report my dietary habits." This statement, or something similar seemed to be the sentiment of all the participants. Fasting blood sugars were provided by participants each session, although participants understood it was only required before and after the COACHING program. The participants stated that they wanted to know their fasting blood sugar prior to the sessions to determine how well they adhered to their diet during that previous week.

Results from the telephone coaching program were compared to the data collected prior to the intervention to make inferences about outcomes associated with the intervention (the $\mathrm{COACH}$ program). Non-parametric analysis was used to determine if there was a difference in each participant's daily fasting blood sugars before and after a six week COACH program. Similar tests were conducted to determine if there was an improvement in the pre-and postknowledge test. Participants received a five--item evaluation to assess their attitudes toward the coaching process and their coach examining the effectiveness and perceived value of their coach and the COACHING experience (Appendix G). 


\section{Measures}

Each participant completed a pre-and post-test on diabetes knowledge. After each test was graded, the scores of each participant were compared to see if improvement was achieved. With the exception of the three participants that scored a 100 on the pre-test, each participant's score improved on their post-test. The fasting blood sugars were obtained via the participants and self-reported to the coach. Both the pre-and post-fasting blood sugars were compared and showed a significant improvement upon completion of the $\mathrm{COACH}$ program. Participants were enthusiastic to engage with the coach during their biweekly morning sessions and all telephone sessions dates were documented throughout the six-weeks sessions.

\section{Data Management}

The investigator collected all data from the participants. Data files were maintained and stored in a locked cabinet that only the investigator could assess.

\section{Data Analysis}

The data were analyzed using (Statistical Product and Service Solutions) SPSS version 21 statistical computerized program. The results of the pre and post-questionnaire scores and the pre-and post-fasting blood sugar levels were entered into the SPSS program. Examination of the pre-post-differences showed that the data were not normally distributed; therefore nonparametric analysis was utilized to determine if there was a statistically significant change in participant's knowledge regarding type 2 diabetes, and in fasting blood sugars after a six-weeks COACH program. 


\section{Section IV}

\section{Findings}

Ten participants met the inclusion criteria and were enrolled in the $\mathrm{COACH}$ program. Seven participants completed the program; there was a 30\% program attrition rate. The gender makeup of the initial sample was two males ages 37 and 67, and eight females (age range 27 to 87). Three participants were retired and one worked from home.

Individuals who dropped out of the program included participant \#3 who was unable to participate; \#4, a 51 year-old male who worked two jobs and felt like he did not have the time to commit to the biweekly phone calls for six weeks; and participant \#5, a 48 year old female who worked nights and decided she was unable to remain in the study due to her work schedule.

The remaining participants are briefly described as follows: participant \#1 a 77 year-old retiree (high school graduate) divorced mother of three who resides alone. She was diagnosed with Type 2 Diabetes in 2009. Participant \#2 was a 48 year-old married, mother of one. She was a college graduate who worked from home and was diagnosed with Type 2 Diabetes in 2007. Participant \# 6 was an 87-year old retiree (high school graduate) mother of 10, who was diagnosed with Type 2 Diabetes in 2000. Participant \#7 was a 69-year old divorcee (high school graduate) who travels two to three weeks out of the month for work, was diagnosed with Type 2 Diabetes in 2005. Participant \#8 was a 67-year old male retiree diagnosed with Type 2 Diabetes in 2006 and resides alone.

Participant \#9 a 37-year old male fire fighter diagnosed with Type 2 Diabetes in 2002 and resides with his father. Participant \#10 was a 61-year old married mother of two, and a university employee who was diagnosed with Type 2 Diabetes in 2010. All the participants agreed to be called every Monday and Tuesday morning and had previously attended a diabetes education class. 
Data analysis was conducted upon completion of the six-week COACH study. Variables analyzed included the pre-and post-knowledge test and the pre-and post-fasting blood sugars.

The differences between pre-and post-variables were not normally distributed. (see table below).

Table 1: Pre-and Post-fasting blood sugars

\begin{tabular}{|l|r|r|r|r|r|r|}
\hline \multicolumn{9}{|c|}{ Tests of Normality } \\
\hline & \multicolumn{2}{|c|}{ Kolmogorov-Smirnov ${ }^{\mathrm{a}}$} & \multicolumn{2}{|c|}{ Shapiro-Wilk } \\
\cline { 2 - 7 } & Statistic & df & Sig. & Statistic & df & Sig. \\
\hline Post-minus Pre-Diabetes Mellitus test & .316 & 7 & .033 & .789 & 7 & .032 \\
\hline Post-minus Pre-fasting blood sugars & .430 & 7 & .000 & .568 & 7 & .000 \\
\hline a. Lilliefors Significance Correction & \multicolumn{10}{|c}{} \\
\hline
\end{tabular}

In subsequent non-parametric analysis, the Wilcoxon Signed Ranks test revealed a statistically significant change in the pre-and post-fasting blood sugars $(p=0.018)$. This finding of a significant difference illustrates that participation in the $\mathrm{COACH}$ project was associated with participants' overall success with lowering their fasting blood sugars during the six-week period of the program. Although three out of seven participants received a score of 100 on the preknowledge test, it is worth noting that scores for the other four participants did improve on their post test. However, there was no statistical significance $(p=0.068)$ possibly due to the ceiling effect, and the small sample size.

Table: 2 Descriptive Statistics for the Pre, Post and Difference Variables

\begin{tabular}{|l|r|r|r|r|r|}
\hline \multicolumn{5}{|c|}{ Descriptive Statistics } \\
\hline Pre-Diabetes Mellitus Test Scores & N & Minimum & Maximum & Mean & Std. Deviation \\
\hline Post-Diabetes Mellitus Test Scores & 7 & 36.0 & 100.0 & 81.429 & 24.1927 \\
\hline Difference in Diabetes Mellitus Test Scores & 7 & 64.0 & 100.0 & 89.686 & 14.1807 \\
\hline Pre-Fasting Blood Sugars & 7 & 100.0 & 235.0 & 140.429 & 44.5229 \\
\hline Post-Fasting Blood Sugars & 7 & 88.0 & 138.0 & 116.429 & 16.9200 \\
\hline Difference in Fasting Blood Sugars & 7 & -122.00 & -1.00 & -24.0000 & 43.53160 \\
\hline Valid N (listwise) & 7 & & & & \\
\hline
\end{tabular}

The $\mathrm{COACH}$ evaluation revealed that all participants were pleased overall with the $\mathrm{COACH}$ program. Comments ranged from, "The coach calling made me accountable for what I 
was eating," to "I really enjoyed the $\mathrm{COACH}$ program because it made me more aware of what I was eating and helped me to adjust to a better diet." Although the COACH program was initially implemented with people with cardiovascular disease, research has shown, and this project confirms that the program can be effectively utilized with Type 2 Diabetics within the AfricanAmerican community. 


\section{Section V}

\section{Discussion}

\section{Nursing Implications}

Given the alarming rate of Type 2 Diabetes associated with obesity in the U.S, innovative approaches to diabetes management are needed to prevent complications and enhance quality of life. The results of this project could potentially lead healthcare providers to incorporate telephone coaching into their Type 2 Diabetes glycemic control algorithm under lifestyle modification. The $\mathrm{COACH}$ program can be used as a teaching tool to enhance clinical impact. Inner-city men and women need creative, economical, and culturally oriented interventions to address economic, cultural, and environmental factors that appear to contribute to their risk for Type 2 Diabetes, which, if not addressed, is likely to further increase health disparity.

There are several appealing aspects of this approach. First, The $\mathrm{COACH}$ program demonstrates that telephone coaching, which is being increasingly used in diabetes management and promoting sustainability, seems to be a practical approach to focus on diabetes prevention or management (COACH, 1995). Providing counseling by telephone can increase access for patients who encounter difficulty traveling to a clinical site for consultation. The coaching program appeared to help participants in breaking down broad health goals into smaller, more manageable ones. Second, this study demonstrates that the coach program can be feasibly integrated into primary care clinics without requiring additional resources. Nurse Practitioners may use this approach to develop effective wellness programs in terms of diabetes management and diabetes prevention for those at risk. Although this project included a small number of participant's in only one setting, the $\mathrm{COACH}$ program was well received by people with diabetes as an intervention that teaches skills for exercise and nutrition management. Coaching builds awareness and confidence, and teaches people how to set reasonable, 'do-able' goals to help 
make important changes that impact their health. Coaching expands possibilities by helping people explore options, problem-solve, prioritize, anticipate and manage stumbling blocks, and to make appropriate decisions that fit within their lives. Its whole-person (holistic) approach develops skills that can be applied to all areas of a person's life, as well as benefit diabetes selfmanagement.

It may be further inferred that the life coaching intervention may be culturally compatible, accepted and appreciated by diverse groups, given that it was developed and tested in Australia and successfully adapted in the USA. The COACH Program could possibly be applied to other chronic illnesses such as hypertension, cardiovascular disease, and other conditions that would benefit from positive lifestyle changes. In addition, the COACH program should be tested on a larger scale to evaluate the benefit of a permanent affiliation with a diabetes coach and potentially enhance the available evidence in this population for clinical practice.

This project began with the expectation that utilizing telephone coaching as a part of a Type 2 Diabetes program would have a positive impact on the biomarker tracked and would be an effective supportive intervention for participants. A positive impact on fasting blood sugars, could positively affect Type 2 Diabetes outcomes through enhanced self-efficacy. There remain, however, several questions to be answered: Is the impact something that would be sustained over time?; how effective would this approach be in a diverse population of diabetic patients (i.e., would greater reductions in fasting blood sugars be realized); would patients benefit from a permanent affiliation with a diabetes coach? In addition, the responses from participants indicated that this program was valued and could serve as a reproducible model for other settings. The investigator contend that the demonstrated positive impacts of telephone coaching on attitude and behavior represent a pathway to clinical impact that requires time beyond the end 
of the six-weeks coaching to manifest. This gap in impact could be addressed in the future studies by measuring diet and fasting blood sugars at three months, six months and twelve months intervals.

\section{Strengths and Weakness of the Design}

Pre-experimental design (or a one group pre-test/post test design) is generally utilized as a pilot to determine if a project warrants further investigation. One advantage to this design is that it is inexpensive and one of the simplest forms of research. This project produced rich anecdotes about the willingness of participants to learn better management of their Type 2 Diabetes, given the structured $\mathrm{COACH}$ program, and a willing clinician as a guide. However, a weakness of the design, is a lack of a control group and random assignment.

\section{Limitation of Study}

As in all studies, there are limitations. Recruiting subjects for participation in medical research is a challenging task in general. It is magnified when considering minorities, particularly African Americans adults. Participant recruitment proved challenging in this setting and with this population. The majority of $\mathrm{NCHC}$ patients with Type 2 Diabetes were apprehensive to participate in the $\mathrm{COACH}$ study, even though they had established a rapport with the coach. This was due, in part, to their lack of knowledge regarding research but also their historical fear of research. Nonparticipation of African Americans in research has been linked to the history of racism in medical research (Gamble, 2003). The most powerful example of this is the Tuskegee Syphilis Study.

Another limitation was the investigator's presence during data collection, which could have potentially caused some participants to respond in a socially acceptable manner or simply not to answer honestly. Self-report questionnaires were used to collect data that may have resulted in biased responses. This could affect the findings. Finally, the data collection site was at 
one community health center, which limited access to a more diverse sample of African Americans with Type 2 Diabetes. In addition, the results of this project cannot be generalized to other populations because of the small sample size and convenient sampling.

\section{Future Research}

In this project, a structured coaching program was associated with improved glycemic control among seven African-American men and women with Type 2 Diabetes. Such an approach may represent a pathway to clinical impact that requires time beyond the end of the coaching program. Further investigation is needed to determine what this clinical impact might be, including an experimental design that includes control groups, expanded timelines for posttesting, coaching by clinicians from various health care disciplines, and specific testing of coaching elements that support high-impact patient self-care such as medication-taking and attention to diet and exercise.

Qualitative studies could also be conducted to inform clinicians about strategies that may assist patients to sustain these benefits. Insurance companies are beginning to see the potential in the coach program and could potentially include incentives for all members with Type 2 Diabetes to participate. Anthem Blue Cross Blue Shield, which is the Commonwealth of Virginia's health insurance, is piloting the $\mathrm{COACH}$ program by enrolling members with diabetes, asthma, chronic obstructive pulmonary disease (COPD), and hypertension into a $\mathrm{COACH}$ program implemented by Active Health Management. The incentive for patients with Type 2 Diabetes to participate includes coverage of all of their diabetes supplies without the additional co-pay, as long as they are using One- touch or Acer meters. Telephone coaching sessions are set up according to individual needs, however, members must speak with the coach at least once per quarter or they will be dis-enrolled. Pharmaceutical companies are also joining the testing of this approach by offering diabetes health coaches for those clients on Novo 
Nordisk insulin products. In summary, there are opportunities to evaluate the use of coaching strategies, which need to be conducted by clinicians in consultation with researchers so that results provide valid and reliable outcomes and thus sound guidance for clinical practice. 


\section{References}

American Diabetes Association (2007, 2008, 2013). Diabetes statistics, Retrieved from http://www.diabetes.org/diabetesbasics/diabetes-statistics/

Balkau, B., Mhamdi, L., Oppert, J. M., Nolan, J., Golay, A., Porcellati, F., Laakso, M., \& Ferrannini, E. (2008). Physical activity and insulin sensitivity. American Diabetes Association , 57(10), 2613-2618. doi: 10.2337/db07-1605

Bandura, A. (1977). Self-efficacy: Toward a unifying theory of behavioral change. Cited in Tompkins, M. (2013) Enhancing Self-Efficacy to Achieve Competence. Journal of Cognitive Psychotherapy: An International Quarterly, 27, p. 71-80. Retrieved from http://www.ingentaconnect.com.proxy.library.vcu.edu/content/springer/jcogp/2013/

Behavioral Risk Factor Surveillance System, Retrieved from www.vdh.virginia.gov/ohs/brfss

Carnethon, M. C. (2008). Diabetes prevention in U.S ethnic minorities: Role of the social environment. Journal of the American Dietetic Association, 108, 942-944. Retrieved fromhttp://www.sciencedirect.com.proxy.library.vcu.edu/science/article/pii/S0002822308 0032833

Centers for disease control (2003). National diabetes fact sheet, Retrieved from http://www.cdc.gov/diabetes/pbs/

Centers for disease control (2008). National diabetes fact sheet, Retrieved from http://www.cdc.gov/nchs/data/nhsr/nhsr025.pdf-

Centers for disease control (2011). National diabetes fact sheet, Retrieved from http://www.cdc.gov/diabetes/pbs/

Centers for disease control (2013). National diabetes fact sheet, Retrieved from http://www.cdc.gov/diabetes/pbs/ 
Chow, E., Foster, H., Gonzalez, V., \& Melver, L. (2012). The disparate impact of diabetes on racial/ethnic minority populations. Clinical Diabetes Journal, 30, 130-133. Retrieved from http://www.clinical.diabetesjournals.org

Cowie, C., \& Ederhardt, M. (1995). Socioedemographic characteristics of persons with diabetes. National Institutes of Health, 95(1468), 85-116. Retrieved from http://web.ebscohost.com.proxy.library.vcu.edi/ehost

COACH program,(1995). Retrieved from http://thecoachprogram.com

Diabetes statistics. (2011). Retrieved from http://www.diabetes.org/diabetes-statistics Diabetes and its awful toll quietly emerge as a crisis.

Evans, M. (2007). Evidence-based practice protocol to improve glucose control in individual with type 2 diabetes mellitus. The Journal for Nurse Practitioners, 9, 416-422. Retrieved from http://www.npjournal.org

Flegal, K. M., Tabak, C. J., \& Ogden, C.L. (2006). Overweight in children: Definitions and interpretation. Health Education Research, 21, 755-760. Retrieved from http://her.oxfordjournals.org.proxy.library.vcu.edu/content/21/6/755

Gamble V. (2003). A legacy of distrust: African-Americans and medical research. Retrieved from American Journal of Preventive Medicine, p. 35-38.

Horrowitz, C.R., Colson, K.A., Herbert, P.L., \& Lancaster, K. (2004). Barriers to buying healthy foods for people with diabetes: Evidence of environmental disparities. American Journal of Public Health, 94, 1549-1554. Retrieved from http://www.Americanjournalofpublichealth

Iceland, J., \& Wilkes, R. (2006). Does socioeconomic status matter? Race, class, and residential segregation. Social Problems, 53(2), 248-273. Retrieved from http://www.jstor.org/stable/10.1525/sp.2006.53.2.248 
Kirkman, M., Weinberger, M., Landsman, P., Samsa, G., Shorliffe, E., Simel, D., \& Feussner, J. (1994). A telephone-delivered intervention for patients with type 2 diabtes: Effect on coronary risk factors. Diabetes Care, 17, 840-846. Retrieved from http://www.sciencedirect.com.proxy.library.vcu.edu/science/article/pii/S0002822330718

MacLean, L., White, J., Broughton, S., Robinson, J., Shultz, J., Wilson, M., \& Weeks, D. (2012). Telephone coaching to improve diabetes self-management for rural residents. Clinical Diabetes, 30, 13-16. Retrieved from http://clinical.diabetesjournals.org/

McKenzie, E., \& Shelley, A. (2010). Analysis of the psychosocial impact of a vascular risk factor interventions: Results from a cluster randomized controlled trial in Australian general practice. American Journal of Public Health, 36, 45-52. Retrieved from http://www.ncbi.nlm.nih.gov

Merriam Webster dictionary(2014) Retrieved from Www.merriam-webster.com

Monsivais, P., \& Drewnowski, A. (2007). The rising cost of low-energy-density foods. Journal of American Dietetic Association, 107, 2071-2076.Retrieved from http://www.sciencedirect.com.proxy.library.vcu.edu/science/article/pii/S0002822307018 007

National Health and Nutrition Examination Survey 2009-2010, Retrieved from www.cdc.gov/nchs/nhanes/search/nhanes09-10.aspx

Novo Nordisk Inc. 2015, Retrieved from www.cornerstones4care.com

Odnoletkova, E. A. (2014). Nurse-lead telecoaching of people with type 2 diabetes in primary care: Rationale, design and baseline data of a randomized controlled trial. BioMed Central, 15(24), 1-9. doi: 10.1186/1471-2296-15-24. Retrieved from http://www.cdc.gov/nchs/data/databriefs/db83.pdf 
Ogden, C., Carroll, M., Kit, B., \& Flegal, K. (2012). Prevalence of obesity in the United States. National Health Statistics Reports, 2009-2010. Retrieved from http://www.cdc.gov/nchs/data/databriefs/db82.pdf

Ogden, C. L. and Flegal, K. M. (2010). Changes in Terminology for Childhood Overweight and Obesity. National Health Statistics Reports, 25, 1-6. Retrieved from http://www.cdc.gov/nchs/data/nhsr/nhsr025.pdf

Osborn, C., Cavanaugh, K., Wallison, K., \& Rothman, R. (2010). Self-efficacy links to health literacy and numeracy to glycemic control. Journal of Health Community, 15, 146-158. Retrieved from http://her.oxfordjournals.org.proxy.library.vcu.edu/content21/7/756

Oxford English dictionary 2010. Retrieved from www.oxforddictionaries.com

Prochaska, J., \& DiClemente, C. (1992). Progress in behavior modification. National Health Statistics Reports, 28, 183-218. Retrieved from http://www.cdc.gov/nchs/data/nhsr/nhrs024.pdf

Ryn, M., \& Fu, S. (2003). Paved with good intentions: Do public health and human service providers contribute to racial/ethnic disparities in health? American Journal of Public Health, 93(2), 248-255. Retrieved from http://www.ncbi.nlm.nih.gov/pmc/articles

Schulze, M. B., \& Hu, F. B. (2005). Primary prevention of diabetes: What can be done and how much can be prevented? Annual Review of Public Health, 26, 445-467. Retrieved from http://www.cdc.gov/nchs/data/nhsr/nhrs024.pdf

The COACH program. (1995). Retrieved from http://thecoachprogram.com

United States Census Bureau, American Community Survey 2009, Retrieved from U.S. Census Bureau (2009). http//quickfactscensus.gov/states/51/5195.html United States Department of Agricultural 2010, Retrieved from 
www.usda.gov/wps/portal/usda/usdahome

Valliantos, Shafter and Gottlieb "Transportation and food: The importance of Access" Los Angeles CA: Center for Food and Justice, Urban and Environmental policy institute, 2002. Retrieved from http://www.uepi.oxy.edu

Virginia Department of Health (2010). Diabetes in Virginia. Richmond VA: VDH, Division of Prevention and Health Promotion, Retrieved from https://www.vdh.virginia.gov/ofhs/prevention/diabetes/documents/2010/pdf/diabetes

Wang, Y., Gortmaker, S., Sobol, S., \& Kuntz, A. (2006). Quantification of the effect of energy imbalance on bodyweight. The Lancet, 378(9793), 826-837. Retrieved from http://www.thelancet.com/journals/lancet

World Health Organization (2012), Retrieved from http://www.who.int/diabetes/actionw/en/DANbooklet.pdf

White, R., Beech, B., \& Miller, S. (2009). Health care disparities and diabetes care: Practical considerations for primary care providers. British Medical Journal, 27(3), 105-112. Retrieved from http://www.clinical.diabetesjournals.org

Zhang, Q., Wang, Y. \& Huang, E.S. (2009)._Changes in racial/ethnic disparities in the prevalence of type 2 diabetes by obesity level among US adults. Ethnicity \& Health, 14, 439-457. Retrieved from http://web.ebscohost.com.proxy.library.vcu.edu/ehost/pdfviewer/pdfviewer?vid=16\&sid= d8be5448-6ae5-4c55-a6e6-d017ea766e1c\%40sessionmgr4\&hid=1 


\section{Appendix A}

IRB-HSR \# 17854: Evaluation of a Coaching Program for African Americans with Type 2 Diabetes

\section{STUDY PROCEDURES}

- You will receive a letter welcoming you to the coaching program, and giving you contact information for the person in charge of this study

- We will ask you to participate in 12 coaching telephone calls over the next 6 week period. Phone calls will last about 15 minutes each time.

- Before the telephone sessions start, you will be asked some questions so that we may learn about your knowledge of diabetes. This will take about 15 minutes to complete.

- We will ask you to report a fasting blood sugar value to us. You will not be asked to check any extra blood sugar levels, but we would like to record a blood sugar level that you have taken as part of your self-care.

- You will also receive a folder and calendar. We will ask you to use this folder to keep track of your appointments for telephone calls. You can also use this folder to make notes during the phone calls, and to write down any questions you may wish to ask during the phone calls.

- During the phone calls, we will ask you some questions about your medications, diet, blood sugar levels, and your activity. Please let us know any areas of concern you have about your diabetes, and we will use the remaining time to answer your questions, and to share information about managing diabetes that might be helpful.

- At the end of the six weeks of coaching phone calls, we will ask you to repeat the knowledge quiz for diabetes. We will review the answers to these questions with you.

- We will ask you to report an additional fasting blood sugar level, taken as part of your normal care at home.

- We will also ask you to some questions about the coaching sessions. Please share your honest opinions with us so that we may learn whether this type of care is helpful. This will take about 10 minutes to complete.

- Your study visits are not meant to take the place of any office visits you may need. You will still need to keep any clinic appointments you may have that are part of your medical care.

\section{How long will this study take?}

Your participation in this study will require 12 of study visits over a 6 week period of time. Each visit will last about 15 minutes, thought the first and last visit will be longer because of the questionnaires.

Page 2 of 7

Version Date: 01/15/15 
IRB-HSR \# 17854: Evaluation of a Coaching Program for African Americans with Type 2 Diabetes

All of your study visits will be completed by telephone.

If you want to know about the results before the study is done:

During the study your study leader will let you know of any information that may be important to your health. In addition, as the research moves forward, your study leader will keep you informed of any new findings that may be important for your health or may help you decide if you want to continue in the study. The final results of the research will not be known until all the information from everyone is combined and reviewed. At that time you can ask for more information about the study results.

\section{Other unexpected risks:}

You may have side effects that we do not expect or know to watch for now. Call the study leader if you have any symptoms or problems.

\section{Could you be helped by being in this study?}

You may or may not benefit from being in this study. Possible benefits include learning more about how to manage your diabetes. In addition, information researchers get from this study may help others in the future.

\section{What are the risks of being in this study?}

Someone might see your private information.

\section{What are your other choices if you do not join this study?}

You do not have to be in this study to be treated for your illness or condition. You can get the usual treatment even if you choose not to be in this study. The usual treatment would include continuing to manage your diabetes without the coaching telephone calls.

If you are an employee of UVa your job will not be affected if you decide not to participate in this study.

If you are a student at UVa, your grades will not be affected if you decide not to participate in this study.

\section{Will you be paid for being in this study?}

You will not get any money for being in this study.

\section{Will being in this study cost you any money?}

All of the procedures in this study will be provided at no cost to you or your health insurance.

Page 3 of 7

Version Date: 01/15/15 
IRB-HSR \# 17854: Evaluation of a Coaching Program for African Americans with Type 2 Diabetes

\section{What if you are hurt in this study?}

If you are hurt as a result of being in this study, there are no plans to pay you for medical expenses, lost wages, disability, or discomfort. The charges for any medical treatment you receive will be billed to your insurance. You will be responsible for any amount your insurance does not cover. You do not give up any legal rights, such as seeking compensation for injury, by signing this form.

\section{What happens if you leave the study early?}

You can change your mind about being in the study any time. You can agree to be in the study now and change your mind later. If you decide to stop, please tell us right away. You do not have to be in this study to get services you can normally get at the University of Virginia.

Even if you do not change your mind, the study leader can take you out of the study. Some of the reasons for doing so may include

a) Your study team member is concerned about your health

b) You do not follow instructions

c) The study sponsor closes the study for safety, administrative or other reasons

If you decide to stop being in the study, we will ask you to tell the study team right away.

\section{How will your personal information be shared?}

The UVa researchers are asking for your permission to gather, use and share information about you for this study. If you decide not to give your permission, you cannot be in this study, but you can continue to receive regular medical care at UVA.

\section{If you sign this form, we may collect any or all of the following information} about you:

- Personal information such as name, address and date of birth

- Social Security number ONLY IF you are being paid to be in this study

- Your health information if required for this study. This may include a review of your medical records and test results from before, during and after the study from any of your doctors or health care providers. This may include mental health care records, substance abuse records, and/or HIV/AIDS records.

\section{Who will see your private information?}

- The researchers to make sure they can conduct the study the right way, observe the effects of the study and understand its results

- People or groups that oversee the study to make sure it is done correctly

- The sponsor(s) of this study, and the people or groups it hires to help perform or review this research

Page 4 of 7

Version Date: 01/15/15 
IRB-HSR \# 17854: Evaluation of a Coaching Program for African Americans with Type 2 Diabetes

- Insurance companies or other organizations that may need the information in order to pay your medical bills or other costs of your participation in the study

- Tax reporting offices (if you are paid for being in the study)

- People who evaluate study results, which can include sponsors and other companies that make the drug or device being studied, researchers at other sites conducting the same study, and government agencies that provide oversight such as the Food and Drug Administration (FDA) if the study is regulated by the FDA.

Some of the people outside of UVa who will see your information may not have to follow the same privacy laws that we follow. They may release your information to others, and it may no longer be protected by those laws.

The information collected from you might be published in a medical journal. This would be done in a way that protects your privacy. No one will be able to find out from the article that you were in the study.

A description of this clinical trial will be available on $h t t p: / /$ www.ClinicalTrials.gov, as required by U.S. Law. This Web site will not include information that can identify you. At most, the Web site will include a summary of the results. You can search this Web site at any time.

\section{What if you sign the form but then decide you don't want your private information shared?}

You can change your mind at any time. Your permission does not end unless you cancel it. To cancel it, please send a letter to the researchers listed on this form. Then you will no longer be in the study. The researchers will still use information about you that was collected before you ended your participation.

\section{Please contact the researchers listed below to:}

- Obtain more information about the study

- Ask a question about the study procedures or treatments

- Report an illness, injury, or other problem (you may also need to tell your regular doctors)

- Leave the study before it is finished

- Express a concern about the study

Principal Investigator: Kathryn Reid

University of Virginia School of Nursing

225 Jeanette Lancaster Way

Charlottesville, VA 22903-3388

Telephone: (434)924-0115

Page 5 of 7

Version Date: 01/15/15 
IRB-HSR \# 17854: Evaluation of a Coaching Program for African Americans with Type 2 Diabetes

\section{What if you have a concern about this study?}

You may also report a concern about this study or ask questions about your rights as a research subject by contacting the Institutional Review Board listed below.

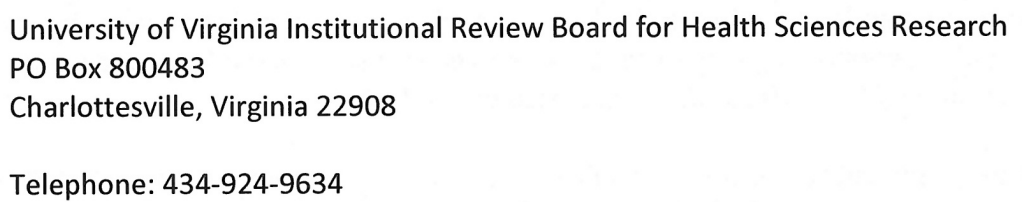

When you call or write about a concern, please give as much information as you can. Include the name of the study leader, the IRB-HSR Number (at the top of this form), and details about the problem. This will help officials look into your concern. When reporting a concern, you do not have to give your name.

\section{Signatures}

What does your signature mean?

Before you sign this form, please ask questions about any part of this study that is not clear to you. Your signature below means that you have received this information and all your questions have been answered. If you sign the form it means that you agree to join the study. You will receive a copy of this signed document.

\section{Consent From Adult}

PARTICIPANT

(SIGNATURE)

To be completed by participant if 18 years of age or older.

(PRINT)

$\overline{\text { PARTICIPANT }} \overline{\text { DATE }}$

PERSON OBTAINING CONSENT

DATE

(PRINT)

(SIGNATURE)

Consent from Impartial Witness

If this consent form is read to the subject because the subject is blind or illiterate, an impartial witness not affiliated with the research or study doctor must be present for the

Page 6 of 7

Version Date: 01/15/15 
IRB-HSR \# 17854: Evaluation of a Coaching Program for African Americans with Type 2 Diabetes

consenting process and sign the following statement. The subject may place an $X$ on the Participant Signature line above.

I agree the information in this informed consent form was presented orally in my presence to the identified individual(s) who has had the opportunity to ask any questions he/she had about the study. I also agree that the identified individual(s) freely gave their informed consent to participate in this trial.

IMPARTIAL WITNESS

IMPARTIAL WITNESS

DATE

(SIGNATURE)

(PRINT)

Page 7 of 7

Version Date: 01/15/15 
Appendix B

Dear participants,

\section{Welcome Letter}

Welcome and thank you for choosing to participate in the six weeks COACH program. The $\mathrm{COACH}$ program uses structured telephone coaching of patients and this approach encourages the patient to self- manage by making relevant behavior changes thus empowering patients to take a greater role in a therapeutic partnership with their health care providers. The COACH program will last for six weeks and each participant will be called twice per week at a mutual time that has been established between the $\mathrm{COACH}$ and the participants. There is a checklist that will be utilized to guide the conversation and a pre and post- test questionnaire will be administered along with fasting blood sugars prior to and at the conclusion of the six weeks $\mathrm{COACH}$ program.. If at any time you have questions please do not hesitate to contact Dianna B White FNP-BC at Norfolk Community Health Center 757-623-0095.

Sincerely

Dianna B White FNP-BC 
Appendix C

Demographic questionnaire

\begin{tabular}{|ll|l|l|l|l|l}
\hline $\begin{array}{l}\text { Year diagnosed } \\
\text { with type 2 DM }\end{array}$ & Age & Education & Income & $\begin{array}{l}\text { Year } \\
\text { attended } \\
\text { diabetes } \\
\text { education } \\
\text { class }\end{array}$ & \\
\hline$\# 1 . \quad 2009$ & 77 & High School & Retired & 2009 & Address \\
\hline$\# 2 . \quad 2007$ & 48 & College Grad & $\$ 43,000$ & 2007 & XXXXXXXXX \\
\hline$\# 6 . \quad 2000$ & 87 & High School & Retired & 2000 & XXXXXXXXX \\
\hline$\# 7 . \quad 2005$ & 69 & High School & $\$ 50,000$ & 2005 & XXXXXXXXX \\
\hline$\# 8 . \quad 2006$ & & High School & Retired & 2006 & XXXXXXXXX \\
\hline$\# 9 . \quad 2002$ & & & & & \\
\hline$\# 10 . \quad 2010$ & 61 & College Grad & $\$ 55,000$ & 2010 & XXXXXXXXX \\
\hline
\end{tabular}


Appendix D

Road to Health Pre and Post Test

Pre-test

Post-test

1. The majority people in my family and community will probably get type 2 diabetes

during their lifetime.

Somewhat agree

Strongly agree

Undecided

Strongly disagree

Somewhat disagree

2. If you develop type 2 diabetes, there is none-thing that can be done to prevent type 2 diabetes from worsening?
a. Somewhat agree
b. Strongly agree
c. Undecided
d. Strongly disagree
e. Somewhat disagree

3. None-thing can be done to prevent you from developing type 2 diabetes.
a. Somewhat agree
b. Strongly agree
c. Undecided
d. Strongly disagree
e. Somewhat disagree 
4. Because there are numerous recommendations about healthy ways to eat; it's impossible to know what to believe.
a. Somewhat agree
b. Strongly agree
c. Undecided
d. Strongly disagree
e. Somewhat disagree

5. What are some of the risk factors for developing type 2 diabetes?

Being overweight /obese

Being over the age of 55

Gestational diabetes (having diabetes when you are pregnant )

Engaging in a sedentary lifestyle (lack of exercise)
a. None of the above
b. Don't' know
c. All of the above

6. Type 2 diabetes

Can lead to heart attack and strokes

Can develop at any age

Can potentially cause problems with the eyes, kidneys and feet More common in older adults
a. None of the above
b. Don't' know
c. All of the above 
7. It's hard for my family to get fresh fruits and vegetables.
a. Somewhat agree
b. Strongly agree
c. Undecided
d. Strongly disagree
e. Somewhat disagree

8. What a person eats makes a big difference in his or her chances of developing type 2 diabetes.
a. Somewhat agree
b. Strongly agree
c. Undecided
d. Strongly disagree
e. Somewhat disagree

9. Exercise or physical activity does affect whether a person develops type 2 diabetes.
a. Somewhat agree
b. Strongly agree
c. Undecided
d. Strongly disagree
e. Somewhat disagree

10. If diabetes runs in a person's family

The person is at increased risk of developing diabetes The person should modify diet and increase exercise
a. None of the above
b. All of the above 
c. Don't' know

11. Identify which of the following foods you think are high in fat:

_ White bread
_ Bananas
_ Macaroni and cheese
Creamed corn

\begin{tabular}{|c|c|}
\hline Crackers & French fries \\
\hline Hamburger & Butter \\
\hline Bologna & Mayonnaise \\
\hline Frozen pizza & Hot dog \\
\hline
\end{tabular}

Identify which of the following foods you think are high in fat:

$\begin{array}{lll}\text { _ White bread } & \text { Crackers } & \text { French fries } \\ \text { Bananas } & \text { Hamburger } & \text { Butter } \\ \text { Macaroni and cheese } & \ldots \text { Bologna } & \text { Mayonnaise } \\ \text { Creamed corn } & \ldots \text { Frozen pizza } & \text { _ Hot dog }\end{array}$


Appendix E

Pre-and Post Fasting blood sugars values

\begin{tabular}{|l|l|l|}
\hline Participants & $\begin{array}{l}\text { Pre-Fasting Blood Sugars } \\
\text { January } 29^{\text {th }}, 2015\end{array}$ & $\begin{array}{l}\text { Post Fasting Blood Sugars } \\
\text { March 2 }\end{array}$ \\
\hline$\# 1$. & & \\
\hline$\# 2$. & & \\
\hline$\# 3$. & & \\
\hline$\# 4$. & & \\
\hline$\# 5$. & & \\
\hline$\# 6$. & & \\
\hline$\# 7$. & & \\
\hline$\# 8$. & & \\
\hline$\# 9$. & & \\
\hline$\# 10$. & & \\
\hline
\end{tabular}


Appendix F

$$
\text { Telephone checklist }
$$

The following questions will be covered in the 15 minute bi-weekly telephone sessions:

1. How is everything going with type 2 diabetes?

2. Are you taking medications for type 2 diabetes mellitus?

3. If yes, what medications and how often?

4. What did your diet consist of over the last 24 hours?

5. Are you self-monitoring your fasting blood glucose levels at home?

6. If yes how often?

7. What were your blood glucose values over the last 24hours?

8. Are you getting exercise of moderate intensity at least three times a week for 30 minutes at a time? 
Appendix G

Diabetes telephone COACH program Evaluation Form

1. What did you like about the $\mathrm{COACH}$ program?

2. What did you not enjoy about the telephone $\mathrm{COACH}$ program?

3. Would you recommend the telephone $\mathrm{COACH}$ program to friends and family?

4. Was the COACH friendly?

5. Will you continue the modified diet and exercise implemented during the $\mathrm{COACH}$ program? 


\section{Appendix H}

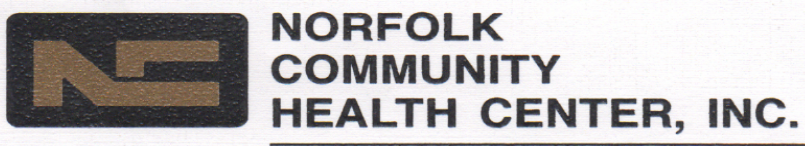

1401 Tidewater Drive, Suite $1 \cdot$ Norfolk, Virginia 23504 (757) 623-0095 - Fax (757) 623-1203

November 16, 2014

Attention: University of Virginia

Institutional Review Board

Re: Dianna Beale White's Project on Evaluating the COACH Program for African Americans with Type 2 Diabetes

This letter serves to verify that the request by Dianna Beale White to conduct the project on evaluating the COACH Program for African Americans with Type 2 Diabetes at the Norfolk Community Health Center is approved.

Please contact me should you need any further information, I can be reached at 757-692-0205

Sincerely

Dr. Angela M. Mercer

Medical Director 
Appendix I

Instructions for Authors

Clinical Diabetes Journal
Clinical Diabetes Instructions for Authors Updated on 19 November 2012.

How do I submit a paper to the journal? About the Journal Editorial Office Contact Info Manuscript Types Manuscript Format Manuscript

Style Requirements Accepted Manuscripts

\section{HOW DO I SUBMIT A PAPER TO THE JOURNAL?}

Please read the complete instructions for authors before submitting your manuscript to Clinical Diabetes. Manuscripts may be submitted via http://mc.manuscriptcentral.com:80/clinical-diabetes.

ABOUT THE JOURNAL The mission of Clinical Diabetes is to provide primary care providers and all clinicians involved in the care of people with diabetes with information on advances and state-of-the-art care for people with diabetes. Clinical Diabetes is also a forum for discussing diabetes-related problems in practice, medical-legal issues, case studies, digests of recent research, and patient education materials.

All submissions to Clinical Diabetes will be reviewed by the editorial team and considered for publication if they contain information that would be helpful to the journal's readership. All articles, whether invited and submitted, should be written with General Practice, Family Practice or Internal Practice Physicians in mind as the main audience.

Clinical Diabetes adheres to the recommendations of the Council of Science Editors as they relate to editorial review procedures and policies, publication procedures and policies, and roles, responsibilities, and rights of editors. Comprehensive information related to the editorial and ethical policies of Clinical Diabetes can be found in Publication Policies and Prodecures.

Clinical Diabetes subscribes to the requirements stated in the Uniform Requirements for Manuscripts (URM) Submitted to Biomedical Journals. Please refer to these requirements when submitting your manuscript.

EDITORIAL OFFICE CONTACT INFORMATION Davida F. Kruger, MSN, APRN-BC, BC-ADM, the editor-in-chief of Clinical Diabetes, began her term with the Winter 2011 issue. Manuscripts should be submitted to 
http://mc.manuscriptcentral.com/clinical-diabetes. Please read the following instructions before submitting your manuscript. Once you have submitted your manuscript, the review process takes between 4 and 6 weeks. Failure to follow the submission instructions may delay the review process.

Editor-in-Chief: Davida F. Kruger, MSN, APRN-BC, BC-ADM Henry Ford Medical Center - NCO Division of Endocrinology, Diabetes, Bone and Mineral Disease. Detroit, Michigan E-mail: dkruger1@hfhs.org

Deputy Editor: Virginia Valentine, CNS, BC-ADM, CDE Diabetes Network, Inc. Albuquerque, New Mexico E-mail:vv@diabetestalk.com

Deputy Editor: John Raymond White, Jr., PA-C, Pharm.D Department of Pharmacotherapy Washington State University Spokane Spokane, Washington E-mail: whitej@wsu.edu

Associate Editor: Arti Bhan, MD Department of Endocrinology Henry Ford Health System Detroit, Michigan E-mail: abhan2@hfhs.org

Associate Editor: John E. Brunner, MD Endocrine \& Diabetes Care Center Toledo, Ohio E-mail: endojack@aol.com

Associate Editor: Stephen Brunton, MD Cabarrus Family Medicine Residency Program Charlotte, North Carolina E-mail: ozdoc@aol.com

Associate Editor: Robert J. Chilton, MD Department of Cardiology University of Texas Health Science Center at San Antonio San Antonio, Texas Email: chiltonr@gmail.com

Associate Editor: Joseph Largay, PAC, CDE Univ. of North Carolina Diabetes Care Center Durham, North Carolina E-mail: jlargay@med.unc.edu

Associate Editor: Gayle M. Lorenzi, RN, CDE University of California at San Diego La Jolla, California E-mail: glorenzi@ucsd.edu

Associate Editor: Melinda Downie Maryniuk, MEd, RD, CDE, FADA Joslin Diabetes Center Boston, Massachusetts E-mail:

melinda.maryniuk@joslin.harvard.edu

Associate Editor: Heather Remtema, MPH, RD, CCRP Department of Endocrinology Henry Ford Health System Detroit, Michigan E-mail: hremtem1@hfhs.org 
MANUSCRIPT TYPES Clinical Diabetes offers long feature articles, which can present either original research or reviews of the literature on a given topic in clinical diabetes care. The journal also includes several standing departments, which offer shorter articles focused on well-defined topic areas. Guidelines for each type of articles are included in separate sections below.

Feature Articles Feature articles on topics related to diabetes in primary practice are published in each issue of Clinical Diabetes. If the article is an invited feature, members of the editorial team will discuss content with invited authors at the time the invitation is extended. Each feature article should be $3000-5000$ words long, including references. The word count for articles that contain tables, figures, or other illustrations should be adjusted down by approximately 500 words for every half-page table, figure, or illustration. (Example: if an author is planning to include two half-page tables, the total word count on the article text (not counting the tables) should be 2000-4000 to ensure enough room for the tables.)

Feature articles should follow the general guidelines set forth in this document. Authors should include a very brief (2-3 sentence) summary of the article, which will appear on the first page of the printed article in lieu of a traditional abstract. Samples articles are available on the journal website.

Guest Editorials Guest editorials should be opinion articles of approximately 800 words in length. The articles should follow the general guidelines set forth in this document. Sample articles are available on the journal website.

"Translating Research to Practice" Articles Articles written for the "Translating Research to Practice" department offer summaries and discussions of current research studies related to diabetes clinical care. Each article should be approximately 1600 words long and should follow the general guidelines set forth in this document. "Translating Research to Practice" articles should be structured in the following format:
A. Title of your article
B. Citation for the research study on which you are writing, including all author names, full title of the research article, journal of publication, volume, page range, and year of publication
C. Reviewed by (your name)
D. Summary of the research article, including brief descriptions of the study objective, design, subjects, methods, results, and conclusion
E. Discussion of the significance of this research, including its applicability to clinical diabetes care, especially in the primary practice setting
F. References

Sample articles are available on the journal website. 
"Practical Pointers" Articles "Practical Pointers" articles offer a discussion of the basics of some aspect of diabetes care. These articles should be 2400-4000 words long and should follow the general guidelines set forth in this document. When appropriate, these articles are accompanied by a patient information page ( 300-400 words at approx. 4th-6th -grade reading level), written for patients, which our readers can photocopy and hand out in their practices. Information pages are written either by the article author, journal staff, or, if time allows, by a free-lance medical and science writer hired by Clinical Diabetes. Sample articles are available on the journal website.

"Case Studies" Articles Articles written for the "Case Studies" department present real patient cases from the authors' practices illustrating specific points in the care of diabetes patients. Each article should be 800-1600 words and should follow the general guidelines set forth in this document. "Case Studies" articles should be structured in the following format:
A. Case study title
B. Your name
C. Brief case presentation, including symptoms at presentation, significant history, physical exam, and lab results
D. Questions raised by this case
E. Commentary
F. Summary of the "clinical pearls" exemplified by this case
G. A brief list of references or suggested readings
Sample articles are available on the journal website.

"Bridges to Excellence" Articles Articles for this department focus on quality improvement initiatives. Submitted articles should provide brief vignettes describing a clinic's or institution's efforts to improve diabetes care. Any attempts to improve the health or health care of people with diabetes, regardless of their outcomes, are welcome. Articles should be 800-1,200 words. Sample articles are available on the journal website.

\section{MANUSCRIPT FORMAT}

Title Page Every manuscript must have an accompanying title page. The title page should include the title; the first name, middle initial, last name, and the highest academic degree of each author; affiliation (in English) of each author; and name, current address, telephone number, fax number, and e-mail address of the corresponding author.

All text and tables should be saved in Word document format. Doing so will allow our Editorial Office to verify the word count and our production staff to turn your 
paper (if accepted) into an article.

Please do not use headers, footers, or endnotes in your paper.

Acknowledgments The acknowledgments should go after the main text and before the reference list. Acknowledgments should contain brief statements of assistance, financial support, and prior publication of the study in abstract form, where applicable.

References The reference list should go at the end of the document, after the main text and acknowledgments (if applicable) and before the tables. References should be numbered in the order that they are cited in the text.

Reference numbers in the text should be in normal type and in parentheses [e.g., "In the study by Norton et al. (23)..."]. Please do not use the footnote/endnote functions found in some word processing programs.

See below for examples of how to style each reference in the reference list.

Tables Tables should be double spaced on separate pages and included the end of the text document, with the table number and title indicated. Tables should be created using Word and the "Insert Table" command; please do not use tabs and/or spaces to create tables, columns, or rows. Tables with internal divisions (Tables $1 \mathrm{~A}$ and $\mathrm{B}$ ) should be submitted as individual tables, i.e., Tables 1 and 2. Symbols for units should be confined to column headings. Abbreviations should be kept to a minimum and defined in the table legend. For footnotes, use the following symbols consecutively, left to right, top to bottom of table: ${ }^{*}, \dagger, \ddagger, \S, \|$, ПI, \#, ${ }^{* *}$, ††, etc.

If tables are taken from other sources, the author must be able to provide written permission for reproduction obtained from the original publisher and author.

Figures Clinical Diabetes uses digital publishing methods throughout the journal production process. If your article is accepted, it will be published both in the printed journal and online. The following sections provide information on how to format your figures to ensure the best possible reproduction of your images.

Size. Figures should be produced at the size they are to appear in the printed journal. Please make sure your figures will fit in one, two, or three columns in width. Multi-paneled figures should be assembled in a layout that leaves the least amount of blank space. 1 column $=13$ picas wide, 2.2 in, $5.6 \mathrm{~cm} 2$ columns $=28$ picas wide, $4.6 \mathrm{in}, 11.7 \mathrm{~cm} 3$ columns $=41$ picas, $6.8 \mathrm{in}, 17.3 \mathrm{~cm}$ 
Font. At $100 \%$ size, fonts should be $8-10$ points and used consistently throughout all figures.

Text. Information on the axes should be succinct, using abbreviations where possible, and the label on the y-axis should read vertically, not horizontally. Key information should be placed in any available white space within the figure; if space is not available, the information should be placed in the legend. In general, figures with multiple parts should be marked $A, B, C$, etc., with a description of each panel included in the legend rather than on the figure.

Line and bar graphs. Lines in graphs should be bold enough to be easily read after reduction, as should all symbols used in the figure. Data points are best marked with the following symbols, again assuring that they will be readily distinguishable after reduction: $\bigcirc \square \square \Delta \boldsymbol{\Delta}_{\text {In }}$ the figure legend, please use words rather than the symbols; e.g., "black circles = group 1; white squares = group 2; black bars = blood glucose; white bars = C-peptide." Bars should be black or white only, unless more than two datasets are being presented; additional bars should be drawn with clear bold hatch marks or stripes, not shades of gray.

Line or bar graphs or flow charts with text should be created in black and white, not shades of gray, which are difficult to reproduce in even tones.

Reproductions. If materials (e.g., figures and/or tables) are taken from other sources, the author must be able to provide written permission for reproduction obtained from the original publisher and author. In addition, the source should be cited at the end of the figure legend. For more information, refer to Permissions: Help for Authors.

Figure legends. Figure legends should be clearly numbered and included the very end of your main text document and should not be included on the separate figure/image files. Please use words to describe symbols used in the figure; e.g., "black circles = group 1; white squares = group 2; black bars = blood glucose; white bars = C-peptide."

Formatting digital files for print reproduction. Computer screens, laser printers, and offset presses are significantly different devices. The ability to print your graphics well on a desktop laser printer does not mean the image can be printed successfully, or at all, on an offset press. Use applications capable of creating high-resolution TIFF, EPS, or JPEG files. It is extremely important that the files be saved at the following resolutions.

Halftones include color or grayscale figures containing pictures only, with no text 
or thin lines, and should be saved at $300 \mathrm{dpi}$.

Combination halftones include color or grayscale figures in combination with text and/or thin lines and should be saved at $600 \mathrm{dpi}$.

Line drawings include artwork made of solid black and white, with no tonal (gray) values, and should be saved at $1200 \mathrm{dpi}$.

Color. Color figures must be created using CMYK color only. Any other format will not be accepted.

Electronic submission of illustrations is encouraged; however, laser-printed, camera-ready artwork may be necessary if submitted electronic files fail to meet criteria for print publishing. Hard-copy versions of figures for accepted manuscripts should be computer-generated laser prints on high-quality laser printer paper. Authors may be asked to prepare new figures if those submitted are not suitable for reproduction. Each figure must have a legend that appears in the text and not on the figure.

MANUSCRIPT STYLE Terminology and Style Articles should be written in clear, concise English following the recommendations for scientific writing found in Scientific Style and Format, the Council of Biology Editors (CBE) style manual (6th ed., 1994, Bethesda, MD, Council of Biology Editors). All accepted manuscripts will be edited according to the CBE style manual and The Chicago Manual of Style (15th ed., 2003, Chicago, IL, The University of Chicago Press) by ADA professional publications staff. The authors are responsible for all statements made in their articles or editorials, including any editing changes made by staff.

The designations type 1 diabetes and type 2 diabetes should be used when referring to the two major forms of diabetes. Abbreviations for diabetes, such as T2D for type 2 diabetes, should not be used. The term diabetic should not be used as a noun. Pharmaceutical agents should be listed by generic name.

Abbreviations Abbreviations should be used only when necessary, e.g., for long chemical names (HEPES), procedures (ELISA), or terms used throughout the article. Abbreviate units of measure only when used with numbers. Abbreviations may be used in tables and figures. The CBE style manual contains lists of standard scientific abbreviations.

Units Clinical laboratory values should be in Syst $\tilde{A} " m e$ International (SI) form. Kilocalories should be used rather than kilojoules. Glycated hemoglobin should be expressed as percentage of total and as standard deviation from mean control 
levels.

References References should be listed according to the following examples and should be numbered in the order that they are cited in the text. All authors must be listed and inclusive page numbers provided. Journal titles should be abbreviated as in the National Library of Medicine's List of Journals Indexed for Medline; for unlisted journals, complete journal titles should be provided. Material that is in press may be cited, but copies of such material may be requested. Authors are responsible for the accuracy of the references.

Journal articles: Banting FG, Best C: The internal secretion of the pancreas. $J$ Lab Clin Med 7:251-266, 1922

Abstracts: Seaborn J: Gastrointestinal side-effects of high-fiber diets in diabetic rats (Abstract). Gut 33:A4304, 1992

Books: Allen FM: Studies Concerning Glycosuria and Diabetes. Bradley RF, Krall LP, Eds. Cambridge, MA, Harvard Univ. Press, 1913

Chapters in books: Stauffacher W, Renold AK: Pathophysiology of diabetes mellitus. In Joslin's Diabetes Mellitus. 11th ed. Marble A, White P, Bradley RF, Krall LP, Eds. Philadelphia, Lea \& Febiger, 1971, p. 35-98

Government publications: Fajans SS (Ed.): Diabetes Mellitus. Washington, DC, U.S. Govt. Printing Office, 1976 (DHEW publ. no. NIH 76-854)

Proceedings and symposia: Steel JM: Prepregnancy counseling and the management of the pregnant woman with diabetes. In Proceedings of the 39th Annual Advanced Postgraduate Course, Orlando, FL, 1992. Alexandria, VA, American Diabetes Association, p. 97-98

Online publications: Beta cell function in type 2 diabetes: glucose metabolism and insulin secretion in the normal pancreas [article online], 1999. Available from http://www.amaryl.com/TXT/Clinical_Management/Overview/beta_cell_failure_T XT.html. Accessed 4 May 2000

REQUIREMENTS Copyright Assignment The American Diabetes Association (ADA) holds the copyright on all material appearing in Clinical Diabetes. All authors must check the appropriate boxes and sign themanuscript submission form, which transfers copyright to the ADA in accordance with the Copyright Revision Act of 1976.

ADA's copyright assignment form addresses permission policies related to reuse 
and post-prints. Please see the revised policy below for the statement of provenance and other conditions:

Reuse. Authors are permitted to reuse portions of their ADA-copyrighted work, including tables and figures, in their own work, and to reuse portions or all of their ADA-copyrighted work for educational purposes, without submitting a request to ADA, provided that the proper citation and copyright information is given.

Post-prints. Authors are permitted to submit the final, accepted version of their manuscript to their funding body, such as $\mathrm{NIH}$, or institution for inclusion in their funding body or institution's database, archive, or repository, or to post the final, accepted version on their personal Web site. These manuscripts may be made freely accessible to the public upon acceptance, provided that the following conditions are observed:

1.Post-prints must include the following statement of provenance and, once the final version has been published in the journal, a link to the final published version of the paper on the journal's Web site: "This is an author-created, uncopyedited electronic version of an article accepted for publication in Clinical Diabetes. The American Diabetes Association (ADA), publisher of Clinical Diabetes, is not responsible for any errors or omissions in this version of the manuscript or any version derived from it by third parties. The definitive publisher-authenticated version is available online at http://clinical.diabetesjournals.org."

2. The version of the manuscript deposited or posted must be identical to the final accepted version, with the exception of the addition of the above statement and any changes necessary to correct errors. Authors may make changes to the posted version to correct mistakes or may issue an erratum at any time. However, the final published version of the manuscript may not be deposited, posted, or later substituted for the post-print.

Duality of Interest All authors must read the ADA Policy Statement on Duality of Interest provided to them by the editorial team and check the appropriate box on the manuscript submission form. Any author who has duality of interest to disclose must attach an additional statement that explains the nature of the duality or conflict of interest. Relevant duality or conflict of interest (or lack thereof) should also be disclosed in the authors' comments to the editor during the submission process.

ACCEPTED MANUSCRIPTS Accepted manuscripts will be scheduled for publication as soon as possible. Correspondence concerning the copyediting and production of accepted manuscripts should be e-mailed to Debbie Fentress, Managing Editor, Clinical Diabetes, at debbiekendall@verizon.net. 
Once an article is submitted, it will be substantively reviewed by the editorial team. A member of the editorial team will contact you if substantive revisions are necessary. Otherwise, your paper will then be forwarded to Clinical Diabetes staff for copyediting for style, grammar, and clarity. The copyedited article will be faxed to you with any final author queries for your final revision and/or approval of the manuscript. Typesetting and page design occur after your final approval. Authors do not review galley proofs. 


\section{American Diabetes Association | Manuscript Submission Form}

Please complete this form and upload it with your submission. Questions regarding this form or its contents should be sent to the Editorial Office at EditorialOffice@diabetes.org.

Manuscript \#:

Title:
Journal:

\section{Author List:}

\section{Statement of Originality and Authorship}

We have read and understand the policies and procedures outlined in the journal's online instructions for authors. We approve the submission of this manuscript to the American Diabetes Association (ADA) for publication and have taken due care to ensure the integrity of this work.

We attest that each author has made an important scientific contribution to the study and has assisted with the drafting or revising of the manuscript, in accordance with the definition of an author as stated by the International Committee of Medical Journal Editors (ICMJE) at http://www.icmje.org/recommendations/. The contributions of each individual Author are described in the manuscript.

We confirm that neither the manuscript nor any part of it has been published or is under consideration for publication elsewhere (abstracts excluded). Any reference to or use of previously published material protected by copyright is explicitly acknowledged in the manuscript. Posting of submitted material on a Web site may be considered prior publication and should be noted in the comments to the editor upon submission.

\section{Potential Conflict of Interest Disclosure}

We confirm that potential conflicts of interest for all Authors, or acknowledgment that no conflicts exist, are included in the manuscript's Acknowledgments section. Disclosures include relationships with a company whose products or services are related to the subject matter of the manuscript. Company is defined as a for-profit concern engaged in the development, manufacture, or sale of pharmaceutical or biomedical devices or supplies. Please refer to the "Publications Policies and Procedures" document on the journal's online instructions for authors for examples of relevant duality of interest.

\section{Copyright Assignment Agreement (select one)}

We hereby assign all rights, including but not limited to the copyright, for this manuscript to ADA upon its acceptance for publication. The rights assigned include, but are not limited to, the sole and exclusive rights to license, sell, subsequently assign, derive, distribute, display, and reproduce this manuscript, in whole or in part, in any format, electronic or otherwise, including formats not in existence at the time this agreement was signed. The Authors hereby warrant that they have not granted or assigned, and shall not grant or assign, the aforementioned rights to any other person, firm, organization, or other entity.

Reuse. Authors are permitted to reuse portions of their ADA-copyrighted work, including tables and figures, in their own work, and to reuse portions or all of their ADA-copyrighted work for educational purposes, provided that the proper citation and copyright information is given.

Post-prints. Authors are permitted to submit the final, accepted version of their manuscript to their funding body, such as $\mathrm{NIH}$, or institution for inclusion in their funding body or institution's database, archive, or repository, or to post the final, accepted version on their personal Web site. These manuscripts may be made freely accessible to the public upon acceptance. See the journal's online instructions for authors for more information.

Work Made for Hire

Authorized Representative:

This work was produced for an employer as a "work made for hire." An authorized representative of that employer must sign here to indicate copyright assignment on behalf of the authors. The employer of the author(s) is permitted to transmit the work on an internal, secure network for use by its employees only, provided that such use is for the promotion of its business enterprise and does not imply endorsement by ADA.

\section{Government Employee}

This work was produced by an employee of the United States Government as part of his/her official duties. No copyright exists, and therefore it cannot be transferred.

The Authors agree to the terms outlined in this document and have provided consent to authorize the Corresponding Author to act on behalf of all Authors and enter into this agreement,

Date: 
Appendix J

\author{
Draft Manuscript
}

Evaluating the COACH PROGRAM for African Americans

with Type 2 Diabetes

Dianna Beale White

DNP, RN, FNP-BC

University of Virginia 


\section{Acknowledgement}

A resounding, thank you to Dr. Reid, my advisor and capstone committee chair, who has been exemplary in guiding my path through the capstone project. Although she juggles numerous demanding rolls within the school of nursing her dedication and commitment to see me through this process never waivered. For this, I am deeply grateful. To Dr. Hinton, thank you for your everlasting support and assistance with the data analysis on this project, your vision saw me through. Dr. Williams, thank you for your insightfulness regarding preparation. Lastly to Dr. Jones, thank you for joining my committee and providing your expertise. Since all committee members were invaluable to the success of this project, I want to thank my entire committee for your commitment and dedication towards education. I was truly blessed to have each of you on my team. 


\begin{abstract}
Purpose: To evaluate changes in knowledge, concerning diet and fasting blood sugars, of African American participants in a six-week $\mathrm{COACH}$ program.
\end{abstract}

Background: An epidemic of Type 2 Diabetes, primarily affecting minorities is emerging. This alarming and disheartening statistics must be addressed (CDC, 2011). The principle objective of this proposal was to evaluate the results of implementing the $\mathrm{COACH}$ program to increase knowledge regarding diet, and to improve glycemic control among African American adults. Study Design: A pre-experimental design evaluated knowledge change and fasting blood sugars related to the $\mathrm{COACH}$ program. The sample size included up to 10 African Americans with Type 2 Diabetes, age 21 or older.

Methods: An 11 item questionnaire and a pre-and post-fasting blood sugar values log was completed by all participants prior to starting the program and after completion of the six week $\mathrm{COACH}$ program. Statistical analysis consisted of the T-test (McNemar Chi-square test for nominal data) using the pre-and post-sets of scores for the same group. Key words: Type 2 Diabetes, African Americans, the COACH program 
Evaluating the $\mathrm{COACH}$ program for African Americans

with Type 2 Diabetes

\section{Section I}

\section{Introduction}

Obesity is a major health issue, and is associated with other serious health problems such as hypertension, cardiovascular diseases, and Type 2 Diabetes Mellitus (Diabetes statistics, 2011). According Ogden and Flegal (2010), obesity is defined as having a body weight greater than or equal to $120 \%$ of desirable body weight. Unfortunately, obesity is, often, a conduit to Type 2 Diabetes.

More than one-third of U.S. adults (35.7\%) are obese. According to the Center for Disease Control and Prevention (CDC, 2013), a dramatic increase in obesity in the United States has occurred over the past 20 years. The average person in the U.S. is more than 24 pounds heavier than in the1980s (Ogden \& Flegal, 2010). This drastic change has propelled both the CDC and the U.S. Department of Human Health Services Office of Disease Prevention and Health Promotion to identify nutrition, physical activity and obesity as leading health determinants (CDC, 2013). Due to the drastic increase of obese individuals worldwide, the World Health Organization (2012) anticipates the incidence of Type 2 Diabetes to double over the next twenty years.

Adult African Americans are at 1.8 times greater risk of being overweight, developing diabetes, and suffering severe complications from the disease than non-Hispanic whites (American Diabetes Association (ADA), 2013). A potential reason for negative outcomes in African Americans diagnosed with Type 2 Diabetes is the lack of knowledge regarding the disease process, which may lead to poor glycemic control through lack of proper diet and exercise (McKenzie \& Shelley, 2010). Effective methods are needed for improving diabetes 
management for African Americans to assist in reducing health disparities within this population (ADA, 2013).

\section{Evidence of the Problem}

Although one in ten adults in the United States have diabetes now, as many as one in three are predicted to have diabetes by 2050 due to an older more diverse population (CDC, 2011). Currently, one out of every five dollars spent on health care in the United States is attributed to the care of someone with diabetes (ADA, 2013). The national health goals set by the United States in 2010 called for a reduction in both the economic and health burden related to diabetes; however, the disease seemingly continues, largely, to be unabated in the United States (CDC, 2011). Multiple studies have shown diabetic complications can be deterred by early diabetes management (CDC, 2011). However, despite numerous advances in technology, there remains a blurred line between recommended and actual diabetes best-care practices.

To determine whether a person has diabetes or pre-diabetes, health care providers have several options available, including an oral glucose tolerance test, a fasting plasma glucose test, and the hemoglobin A1C test. The oral glucose test checks the patient's serum blood glucose levels before, and 2 hours after, he/she ingests a sugary sweet drink. A normal oral glucose tolerance test result is less than $140 \mathrm{mg} / \mathrm{dl}$. Pre-diabetes is indicated by $140 \mathrm{mg} / \mathrm{dl}$ to $199 \mathrm{mg} / \mathrm{dl}$ result and a diabetes diagnosis is indicated by a yield of $200 \mathrm{mg} / \mathrm{dl}$ or higher. The normal levels of the fasting plasma glucose test (FPG) are less than $100 \mathrm{mg} / \mathrm{dl}$, pre-diabetes $100 \mathrm{mg} / \mathrm{dl}$ to $125 \mathrm{mg} / \mathrm{dl}$ and diabetes $126 \mathrm{mg} / \mathrm{dl}$ or higher. The hemoglobin A1C, a serum blood test, can also be used. If the A1C is $5.7 \%$ or less, the client is not predisposed for Type 2 Diabetes; $5.7 \%$ to $6.4 \%$ indicates pre diabetes; and 6.5\% or greater indicates Type 2 Diabetes (ADA, 2013). Any of these tests can be utilized to diagnose pre-diabetes or diabetes; however, the American Diabetes Association (ADA) recommends the FPG because it is quicker and cheaper than a serum blood 
test. Maintaining blood glucose levels below $100 \mathrm{mg} / \mathrm{dl}$ can prevent or delay many of the complications and costs associated with Type 2 Diabetes Mellitus.

Reducing the complications related to Type 2 Diabetes requires the patient to learn how to successfully self-manage the disease (Osborn, Cavanaugh, Wallison \& Rothman, 2010).

Unfortunately, without sustained support, few people achieve their goals or master the tasks that will allow them to live healthy lives and inadvertently reduce their risk of costly complications and/or co-morbidities (Osborn et al., 2010). Healthcare providers have long recognized the need to provide culturally sensitive health education programs to enhance the health awareness among ethnic groups (ADA, 2011). Consequently, programs such as the Coaching people on Achieving Cardiovascular Health (COACH program), an evidence-based telephone coaching program, can be utilized to improve the health education of patients with chronic illnesses including Type 2 Diabetes (The COACH, 1995).

\section{Purpose of the Project}

The purpose of this project is to test the feasibility of the $\mathrm{COACH}$ program to influence the disease management knowledge of African Americans with Type 2 Diabetes. Specifically, this project will examine whether participants improve their scores on diabetes management knowledge, as well as demonstrate a decrease in fasting blood sugar levels after participating in the COACH program for six-weeks.

\section{Theoretical Framework}

The Social Cognitive Theory (Bandura, 1977) is used as the theoretical framework that informs this evaluation concerning the extent to which knowledge is gained through the $\mathrm{COACH}$ program among African-American adults with Type 2 Diabetes. Social Cognitive Theory stems from the social learning theory with a heavy emphasis on cognitive concepts (Bandura, 1977). Bandura's Social Cognitive Theory focuses on how children and adults operate cognitively in 
terms of their social experiences. According to Bandura, there are three main factors that influence behavior, and those factors can enhance behavior modifications of people with Type 2 Diabetes. These factors include:

1. Self-efficacy: confidence in one's ability to take action and overcome barriers;

2. Goals: knowledge and skill to perform a given behavior in relation to their own personal standards and effective self-reaction; and

3. Outcome expectancies: anticipated outcomes of a behavior individuals and communities adapt to behaviors that produce a positive outcome.

The $\mathrm{COACH}$ program interventions are expected to promote identification and increase awareness of self-management of diabetes symptoms, and encourage adoption of healthy behaviors to prevent complications or co-morbidities (Villanatos, Shaffer \& Gottlieb, 2002).

Although the Social Cognitive Theory is a grand theory, it provides a useful framework concerning the extent to which the $\mathrm{COACH}$ program will influence self-efficacy to modify or change diet and physical activity behaviors. The central emphasis of the Social Cognitive Theory is to understand and predict individual and group behaviors and to identify methods by which behavior can be modified or changed; it is frequently used to support interventions aimed at personality development, behavioral pathology, and health promotion (Bandura, 1977). 


\section{Section II}

\section{Review of the Literature}

A systematic review of relevant professional literature was conducted utilizing electronic databases including Ovid Medline, Pub Med, CINAHL, Cochrane and Google Scholar. Key search terms included "obesity", "type 2 diabetes", "the COACH program”, "African Americans" and a combination of these terms. The search was limited to the English language and the years 2004-2014 for Medline. No date limit was placed on the other databases. The initial search yielded 18,000 potential publications. A specific search including the terms: "COACH program and Nursing" narrowed the field to 50 additional publications. Excluded were non- English language publications. For the purpose of this project, only the studies addressing the $\mathrm{COACH}$ program, African Americans, Type 2 Diabetes, risk factors including socioeconomics, and lack of knowledge regarding risk for Type 2 Diabetes were selected yielding 28 articles.

\section{African Americans and Obesity}

According to the National Health Interview Survey (2012), approximately 13.2 million African Americans ages 20 and older were diagnosed with Type 2 Diabetes or were declared to be at risk for Type 2 Diabetes. A significant factor that places African Americans at risk is the definition that defines one as being obese or overweight: having a body mass greater than $25 \mathrm{~kg} / \mathrm{m}$ (Ogden \& Flegal, 2010). National population examinations have consistently reported an excess prevalence of obesity among African Americans, Latino Americans, and Native Americans as compared with non- Hispanic Whites (Chow, Foster, Gonzalez \& Melver, 2012). Although Type 2 Diabetes can occur in the absence of being overweight and obese, approximately 85 percent of people with Type 2 Diabetes are, indeed, overweight or obese (Zhang, Wang, \& Huang, 2009). 


\section{Socioeconomics-status and Type 2 Diabetes}

Socioeconomic status is commonly defined as a combination of education, income, and occupation, which generally determines one's access to health knowledge and health resources (Iceland \& Wilkes, 2006). In many parts of the United States, ethnicity is closely correlated with socioeconomic status. For example, African Americans are disproportionately overrepresented among those with lower socioeconomic status in both urban and rural parts of the United States (Iceland \& Wilkes, 2006).

Minorities of low socioeconomic status tend to also have less access to healthy foods and safe spaces for physical activity. It is well documented that the benefits of regular physical exercise include increased insulin sensitivity, increased glucose tolerance, increased mitochondrial function and increased muscle glucose uptake, decreases risk factors leading to obesity and Type 2 Diabetes. A sedentary lifestyle is the number one culprit that leads to obesity and Type 2 Diabetes (Balkau et al., 2008).

Research on food economics describes an inverse association between the cost of food and their energy density (Monsivais \& Drewnoski, 2007). For example, concentrated sugars, oils, and fats are the least expensive and more energy dense. In contrast, fresh vegetables, fruits, and whole grains are more expensive. Similarly, lean sources of protein such as fish, lean cuts of pork and beef typically cost more than their higher-fat counterparts. African Americans typically consume large amounts of sodium, fat and sugar with minimum amounts of fresh fruits, vegetables and whole grains (Monsivais \& Drewnoski, 2007). Diet is the pinnacle of managing diabetes, and poor dietary habits demonstrated by many African Americans put them at risk for having very poor glycemic control (CDC, 2008).

Within both urban and rural communities, African Americans live in areas that are considered "food deserts" Food deserts, as defined by Oxford (2010), are geographic areas in 
which access to affordable healthy food options are severely restricted or simply do not exist due to the lack of supermarkets within the transportation line. The United States Department of Agricultural (2010) reported that 2.2 Percent of all US households reside more than one mile away from a supermarket and the residents of that household do not own a car, and are therefore denied access to affordable and nutritious food. Researchers have identified a strong correlation between food insecurity an increase in diabetes rate (Chow, Foster, Gonzalez \& Melver, 2012).

\section{Lack of knowledge regarding management of type 2 diabetes}

Poor health outcomes among African American patients with Type 2 Diabetes can be explained by their lack of knowledge regarding the disease process and standard diabetes care, and poor communication with their healthcare providers. McKenzie \& Shelley (2010) reported that African Americans have a general knowledge deficit concerning Type 2 Diabetes, the risk factors of diabetes, and the prevention of the disease. Type 2 Diabetes is a multifactorial disease that is influenced by environmental, social, cultural and psychological factors, therefore healthcare providers must adequately address the barriers to Type 2 Diabetes self management and identify strategies to overcome such barriers (Kirkman et al., 1994).

\section{Utilizing the COACH program as a teaching method}

The COACH program was developed in Australia in 1995, and is an evidence-based coaching program centrally focused on the prevention of chronic diseases (The COACH program, 1995). It was developed to close the gap between the recommended treatment guidelines and the actual care that patients receive. The $\mathrm{COACH}$ program used the telephone to provide structured coaching to participants diagnosed with a chronic illness. This pragmatic intervention encouraged the patient to self-manage their disease by making relevant behavior changes, thus empowering them to play a greater role in their care with their providers (Ryn \& $\mathrm{Fu}, 2003)$. The $\mathrm{COACH}$ program leaders conducted telephone sessions with the participants to 
help them identify lifestyle issues, monitor their disease, encourage adherence to their medication regimen, and consult with their primary care provider and allied health services (The COACH program, 1995).

A plan of action was developed for each patient based on the national clinical guidelines for the specific disease process. Patients were provided targeted goals to achieve within the sixweek timeline. The timeline can be shorter, however, six-weeks was the recommended minimum, depending on the client's needs. Each session builds upon the previous task-oriented session. Patients received, on average, approximately six coaching sessions over the course of six-weeks, although additional coaching can be provided if warranted. During these sessions patients were educated about various appropriate lifestyles measures and behaviors (The COACH program, 1995).

Improving lifestyle behaviors through telephone COACHING has shown to be a cost effective approach to improving healthy lifestyle behaviors in a variety of conditions, including diabetes self-management (Schulze \& Hu, 2005). Telephone interventions may increase self-care adherence by developing tailored interventions that actively involve patients with individualized goals while subsequently addressing the barriers each patient faces. Patient education is also commonly recognized as an integral component of diabetes treatment. The COACH program's primary objective is to reduce the knowledge and treatment gap while motivating patients to assert appropriate lifestyle modifications and medical therapy (The COACH, 1995).

Although there are numerous techniques and strategies available to provide adequate education in problem-solving skills related to diabetes management, different educational programs produce different results in terms of the clinical cost-effectiveness (Odnoletkova et al., 2014). Due to the complexity of some interventions it is difficult to detect the direct effect of the patient education related to the actual outcomes. Patient education programs can be difficult to 
describe and difficult to reproduce in other settings. However, the COACH program is a wellestablished target driven telephone intervention that is cost effective to utilize and not complicated to implement (The $\mathrm{COACH}, 1995)$. 


\section{Section III}

\section{Methods}

\section{Project overview}

The purpose of this project was to implement a six-week telephone coaching program for African Americans with Type 2 Diabetes to evaluate the changes in knowledge concerning disease management with the projected outcomes of: (1) Improving scores on participants' diabetes knowledge comparing pre-test to post-test, and (2) observing a decrease in participant's fasting blood sugars after the six weeks COACH program. The telephone coach supported the participant in their lifestyle modifications to facilitate successful management of their daily routines. These routines include implementing appropriate self-care strategies, monitoring blood glucose, taking prescribed medications, and following diet and exercise regimens.

\section{Project design}

A pre-experimental study design (one group pre-post-test) with a convenient sample size was used. The purpose for selecting such a design was to examine whether the COACH program would be associated with the intended effect of increase knowledge regarding Type 2 Diabetes and improve fasting blood sugars with the project's participants. Data were collected on the participants' pre-and post-the intervention to access the participant's knowledge, and their fasting blood sugars following their participation in the six-weeks COACH program.

\section{Setting}

Participants were recruited from a community health center in Hampton Roads Virginia. It is conveniently located along the bus lines in an urban community to provide accessible health care. A broad range of services are provided for the adult patients including physical examinations for school and employment, management of diabetes and hypertension, treatment 
of numerous acute and chronic illnesses, and preventive services such as cancer screening, and family planning. The personnel hierarchy is as follows: the primary care physician and the nurse practitioner are responsible for delivering comprehensive community-oriented primary care to the 650 clients enrolled in at the community health center.

\section{Sample}

A convenience sample of ten volunteer African American men and women were recruited for this project who met the following inclusion criteria: African American; aged 21 or older; diagnosed with Type 2 Diabetes; currently receiving primary healthcare at the community health center; attended at least one standard ADA outpatient Diabetes Mellitus educational class; speaks English fluently; and are able to provide consent to participate in the $\mathrm{COACH}$ program.

Exclusion criteria included those who were: under age 21, non-English speakers, and had an active cancer diagnosis.

\section{Protection of Human Subjects}

Approval to implement this project was obtained from the University of Virginia Institutional Review Board for Health Sciences Research, protocol \# 17854. Participants were ensured that ethical principles were adhered to in this study, their information would be reported in aggregated form, and individual participants data would not be identifiable.

\section{Intervention}

The COACH program implemented in this study consisted of twelve calls from a coach, each lasting approximately 15 minutes per session. Calls were conducted twice per week over a six-week period. During each call the coach reinforced positive change. When program participants had difficulty achieving goals, the coach gently questioned them about obstacles and possible solutions. The coach was equipped with a telephone checklist to effectively conduct her calls. Medical advice was not provided during the coaching sessions. 


\section{Procedures}

After obtaining approval from the University of Virginia Institutional Review Board \#17854, providers at Norfolk Community Health Center informed their patients of the project and referred patients who wished to participate in the program to the coach. Once the patient agreed to participate in the project, he/she signed the consent form (Appendix A). Upon enrollment in the project, the participant received a letter to welcome him/her into the $\mathrm{COACH}$ program (Appendix B).

While participating in the $\mathrm{COACH}$ program, participants continued to receive their routine care from their primary care provider. A demographic questionnaire was utilized to collect information and before the pre-test (Appendix C). Information collected included the following: age, education, income, residential locality in the Hampton Roads area, and the year the participant was diagnosed with Type 2 Diabetes. Each participant completed a baseline Type 2 Diabetes pre knowledge test generated by the Road to Health program (Appendix D). The National Diabetes Educational Program in direct partnership with the National Institutes of Health and the Centers developed this knowledge test for disease and prevention (CDC, 2011).

A self-reported fasting blood sugar (finger-stick) test result was collected prior to the start of the COACHING program (Appendix E). Once the initial demographic, pre-knowledge test, and fasting blood sugars were collected, the telephone coaching documentation form was filed in each participant's chart. At that time the six-weeks telephone coaching program began. At the conclusion of the six-weeks telephone coaching program, diabetes knowledge and fasting blood sugar measurements were reassessed.

The $\mathrm{COACH}$ program includes twelve coaching telephone sessions that were implemented twice per week for each participant by the investigator (Appendix F). After the first week's sessions the participants and coach agreed upon the time for the calls --Monday and 
Tuesdays of the remainder weeks starting at 8:30 am. The phone calls lasted approximately 15 minutes per session and occurred over a six-week's period. The investigator/COACH was afforded the time at NCHC to conduct these biweekly calls prior to seeing scheduled patients in the office. Both the first and last sessions were slightly longer than 15 minutes each due to the time needed to administer pre-and post-knowledge test as well as to complete the COACH evaluation.

Participants in the program were often eager to provide details regarding their maintenance of their diet over the weekends. Often the discussion would lend itself to the participant's fasting blood sugars and the impact they perceived the $\mathrm{COACH}$ program was having on their improved fasting blood sugar even on the days the coach did not call. One participant reported he/she stayed on the prescribed diet because, "I knew I would have to report my dietary habits." This statement, or something similar seemed to be the sentiment of all the participants. Fasting blood sugars were provided by participants each session, although participants understood it was only required before and after the COACHING program. The participants stated that they wanted to know their fasting blood sugar prior to the sessions to determine how well they adhered to their diet during that previous week.

Results from the telephone coaching program were compared to the data collected prior to the intervention to make inferences about outcomes associated with the intervention (the $\mathrm{COACH}$ program). Non-parametric analysis was used to determine if there was a difference in each participant's daily fasting blood sugars before and after a six week COACH program. Similar tests were conducted to determine if there was an improvement in the pre-and postknowledge test. Participants received a five--item evaluation to assess their attitudes toward the coaching process and their coach examining the effectiveness and perceived value of their coach and the COACHING experience (Appendix G). 


\section{Measures}

Each participant completed a pre-and post-test on diabetes knowledge. After each test was graded, the scores of each participant were compared to see if improvement was achieved. With the exception of the three participants that scored a 100 on the pre-test, each participant's score improved on their post-test. The fasting blood sugars were obtained via the participants and self-reported to the coach. Both the pre-and post-fasting blood sugars were compared and showed a significant improvement upon completion of the $\mathrm{COACH}$ program. Participants were enthusiastic to engage with the coach during their biweekly morning sessions and all telephone sessions dates were documented throughout the six-weeks sessions.

\section{Data Management}

The investigator collected all data from the participants. Data files were maintained and stored in a locked cabinet that only the investigator could assess.

\section{Data Analysis}

The data were analyzed using (Statistical Product and Service Solutions) SPSS version 21 statistical computerized program. The results of the pre and post-questionnaire scores and the pre-and post-fasting blood sugar levels were entered into the SPSS program. Examination of the pre-post-differences showed that the data were not normally distributed; therefore nonparametric analysis was utilized to determine if there was a statistically significant change in participant's knowledge regarding type 2 diabetes, and in fasting blood sugars after a six-weeks $\mathrm{COACH}$ program. 


\section{Section IV}

\section{Findings}

Ten participants met the inclusion criteria and were enrolled in the $\mathrm{COACH}$ program. Seven participants completed the program; there was a 30\% program attrition rate. The gender makeup of the initial sample was two males ages 37 and 67, and eight females (age range 27 to 87). Three participants were retired and one worked from home.

Individuals who dropped out of the program included participant \#3 who was unable to participate; \#4, a 51 year-old male who worked two jobs and felt like he did not have the time to commit to the biweekly phone calls for six weeks; and participant \#5, a 48 year old female who worked nights and decided she was unable to remain in the study due to her work schedule.

The remaining participants are briefly described as follows: participant \#1 a 77 year-old retiree (high school graduate) divorced mother of three who resides alone. She was diagnosed with Type 2 Diabetes in 2009. Participant \#2 was a 48 year-old married, mother of one. She was a college graduate who worked from home and was diagnosed with Type 2 Diabetes in 2007. Participant \# 6 was an 87-year old retiree (high school graduate) mother of 10, who was diagnosed with Type 2 Diabetes in 2000. Participant \#7 was a 69-year old divorcee (high school graduate) who travels two to three weeks out of the month for work, was diagnosed with Type 2 Diabetes in 2005. Participant \#8 was a 67-year old male retiree diagnosed with Type 2 Diabetes in 2006 and resides alone.

Participant \#9 a 37-year old male fire fighter diagnosed with Type 2 Diabetes in 2002 and resides with his father. Participant \#10 was a 61-year old married mother of two, and a university employee who was diagnosed with Type 2 Diabetes in 2010. All the participants agreed to be called every Monday and Tuesday morning and had previously attended a diabetes education class. 
Data analysis was conducted upon completion of the six-week COACH study. Variables analyzed included the pre-and post-knowledge test and the pre-and post-fasting blood sugars.

The differences between pre-and post-variables were not normally distributed. (see table below).

Table 1: Pre-and Post-fasting blood sugars

\begin{tabular}{|l|r|r|r|r|r|r|}
\hline \multicolumn{9}{|c|}{ Tests of Normality } \\
\hline & \multicolumn{2}{|c|}{ Kolmogorov-Smirnov ${ }^{\mathrm{a}}$} & \multicolumn{3}{|c|}{ Shapiro-Wilk } \\
\cline { 2 - 7 } & Statistic & df & Sig. & Statistic & df & Sig. \\
\hline Post-minus Pre-Diabetes Mellitus test & .316 & 7 & .033 & .789 & 7 & .032 \\
\hline Post-minus Pre-fasting blood sugars & .430 & 7 & .000 & .568 & 7 & .000 \\
\hline a. Lilliefors Significance Correction & \multicolumn{10}{|l}{} \\
\hline
\end{tabular}

In subsequent non-parametric analysis, the Wilcoxon Signed Ranks test revealed a statistically significant change in the pre-and post-fasting blood sugars $(p=0.018)$. This finding of a significant difference illustrates that participation in the $\mathrm{COACH}$ project was associated with participants' overall success with lowering their fasting blood sugars during the six-week period of the program. Although three out of seven participants received a score of 100 on the preknowledge test, it is worth noting that scores for the other four participants did improve on their post test. However, there was no statistical significance $(p=0.068)$ possibly due to the ceiling effect, and the small sample size.

Table: 2 Descriptive Statistics for the Pre, Post and Difference Variables

\begin{tabular}{|l|r|r|r|r|r|}
\hline \multicolumn{5}{|c|}{ Descriptive Statistics } \\
\hline Pre-Diabetes Mellitus Test Scores & N & Minimum & Maximum & Mean & Std. Deviation \\
\hline Post-Diabetes Mellitus Test Scores & 7 & 36.0 & 100.0 & 81.429 & 24.1927 \\
\hline Difference in Diabetes Mellitus Test Scores & 7 & 64.0 & 100.0 & 89.686 & 14.1807 \\
\hline Pre-Fasting Blood Sugars & 7 & 100.0 & 235.0 & 140.429 & 44.5229 \\
\hline Post-Fasting Blood Sugars & 7 & 88.0 & 138.0 & 116.429 & 16.9200 \\
\hline Difference in Fasting Blood Sugars & 7 & -122.00 & -1.00 & -24.0000 & 43.53160 \\
\hline Valid N (listwise) & 7 & & & & \\
\hline
\end{tabular}

The $\mathrm{COACH}$ evaluation revealed that all participants were pleased overall with the $\mathrm{COACH}$ program. Comments ranged from, "The coach calling made me accountable for what I 
was eating," to "I really enjoyed the COACH program because it made me more aware of what I was eating and helped me to adjust to a better diet." Although the $\mathrm{COACH}$ program was initially implemented with people with cardiovascular disease, research has shown, and this project confirms that the program can be effectively utilized with Type 2 Diabetics within the AfricanAmerican community. 


\section{Section V}

\section{Discussion}

\section{Nursing Implications}

Given the alarming rate of Type 2 Diabetes associated with obesity in the U.S, innovative approaches to diabetes management are needed to prevent complications and enhance quality of life. The results of this project could potentially lead healthcare providers to incorporate telephone coaching into their Type 2 Diabetes glycemic control algorithm under lifestyle modification. The $\mathrm{COACH}$ program can be used as a teaching tool to enhance clinical impact. Inner-city men and women need creative, economical, and culturally oriented interventions to address economic, cultural, and environmental factors that appear to contribute to their risk for Type 2 Diabetes, which, if not addressed, is likely to further increase health disparity.

There are several appealing aspects of this approach. First, The $\mathrm{COACH}$ program demonstrates that telephone coaching, which is being increasingly used in diabetes management and promoting sustainability, seems to be a practical approach to focus on diabetes prevention or management (COACH, 1995). Providing counseling by telephone can increase access for patients who encounter difficulty traveling to a clinical site for consultation. The coaching program appeared to help participants in breaking down broad health goals into smaller, more manageable ones. Second, this study demonstrates that the coach program can be feasibly integrated into primary care clinics without requiring additional resources. Nurse Practitioners may use this approach to develop effective wellness programs in terms of diabetes management and diabetes prevention for those at risk. Although this project included a small number of participant's in only one setting, the COACH program was well received by people with diabetes as an intervention that teaches skills for exercise and nutrition management. Coaching builds awareness and confidence, and teaches people how to set reasonable, 'do-able' goals to help 
make important changes that impact their health. Coaching expands possibilities by helping people explore options, problem-solve, prioritize, anticipate and manage stumbling blocks, and to make appropriate decisions that fit within their lives. Its whole-person (holistic) approach develops skills that can be applied to all areas of a person's life, as well as benefit diabetes selfmanagement.

It may be further inferred that the life coaching intervention may be culturally compatible, accepted and appreciated by diverse groups, given that it was developed and tested in Australia and successfully adapted in the USA. The COACH Program could possibly be applied to other chronic illnesses such as hypertension, cardiovascular disease, and other conditions that would benefit from positive lifestyle changes. In addition, the COACH program should be tested on a larger scale to evaluate the benefit of a permanent affiliation with a diabetes coach and potentially enhance the available evidence in this population for clinical practice.

This project began with the expectation that utilizing telephone coaching as a part of a Type 2 Diabetes program would have a positive impact on the biomarker tracked and would be an effective supportive intervention for participants. A positive impact on fasting blood sugars, could positively affect Type 2 Diabetes outcomes through enhanced self-efficacy. There remain, however, several questions to be answered: Is the impact something that would be sustained over time?; how effective would this approach be in a diverse population of diabetic patients (i.e., would greater reductions in fasting blood sugars be realized); would patients benefit from a permanent affiliation with a diabetes coach? In addition, the responses from participants indicated that this program was valued and could serve as a reproducible model for other settings. The investigator contend that the demonstrated positive impacts of telephone coaching on attitude and behavior represent a pathway to clinical impact that requires time beyond the end 
of the six-weeks coaching to manifest. This gap in impact could be addressed in the future studies by measuring diet and fasting blood sugars at three months, six months and twelve months intervals.

\section{Strengths and Weakness of the Design}

Pre-experimental design (or a one group pre-test/post test design) is generally utilized as a pilot to determine if a project warrants further investigation. One advantage to this design is that it is inexpensive and one of the simplest forms of research. This project produced rich anecdotes about the willingness of participants to learn better management of their Type 2 Diabetes, given the structured $\mathrm{COACH}$ program, and a willing clinician as a guide. However, a weakness of the design, is a lack of a control group and random assignment.

\section{Limitation of Study}

As in all studies, there are limitations. Recruiting subjects for participation in medical research is a challenging task in general. It is magnified when considering minorities, particularly African Americans adults. Participant recruitment proved challenging in this setting and with this population. The majority of NCHC patients with Type 2 Diabetes were apprehensive to participate in the $\mathrm{COACH}$ study, even though they had established a rapport with the coach. This was due, in part, to their lack of knowledge regarding research but also their historical fear of research. Nonparticipation of African Americans in research has been linked to the history of racism in medical research (Gamble, 2003). The most powerful example of this is the Tuskegee Syphilis Study.

Another limitation was the investigator's presence during data collection, which could have potentially caused some participants to respond in a socially acceptable manner or simply not to answer honestly. Self-report questionnaires were used to collect data that may have resulted in biased responses. This could affect the findings. Finally, the data collection site was at 
one community health center, which limited access to a more diverse sample of African Americans with Type 2 Diabetes. In addition, the results of this project cannot be generalized to other populations because of the small sample size and convenient sampling.

\section{Future Research}

In this project, a structured coaching program was associated with improved glycemic control among seven African-American men and women with Type 2 Diabetes. Such an approach may represent a pathway to clinical impact that requires time beyond the end of the coaching program. Further investigation is needed to determine what this clinical impact might be, including an experimental design that includes control groups, expanded timelines for posttesting, coaching by clinicians from various health care disciplines, and specific testing of coaching elements that support high-impact patient self-care such as medication-taking and attention to diet and exercise.

Qualitative studies could also be conducted to inform clinicians about strategies that may assist patients to sustain these benefits. Insurance companies are beginning to see the potential in the coach program and could potentially include incentives for all members with Type 2 Diabetes to participate. Anthem Blue Cross Blue Shield, which is the Commonwealth of Virginia's health insurance, is piloting the $\mathrm{COACH}$ program by enrolling members with diabetes, asthma, chronic obstructive pulmonary disease (COPD), and hypertension into a $\mathrm{COACH}$ program implemented by Active Health Management. The incentive for patients with Type 2 Diabetes to participate includes coverage of all of their diabetes supplies without the additional co-pay, as long as they are using One- touch or Acer meters. Telephone coaching sessions are set up according to individual needs, however, members must speak with the coach at least once per quarter or they will be dis-enrolled. Pharmaceutical companies are also joining the testing of this approach by offering diabetes health coaches for those clients on Novo 
Nordisk insulin products. In summary, there are opportunities to evaluate the use of coaching strategies, which need to be conducted by clinicians in consultation with researchers so that results provide valid and reliable outcomes and thus sound guidance for clinical practice. 


\section{References}

American Diabetes Association (2007, 2008, 2013). Diabetes statistics, Retrieved from http://www.diabetes.org/diabetesbasics/diabetes-statistics/

Balkau, B., Mhamdi, L., Oppert, J. M., Nolan, J., Golay, A., Porcellati, F., Laakso, M., \& Ferrannini, E. (2008). Physical activity and insulin sensitivity. American Diabetes Association , 57(10), 2613-2618. doi: 10.2337/db07-1605

Bandura, A. (1977). Self-efficacy: Toward a unifying theory of behavioral change. Cited in Tompkins, M. (2013) Enhancing Self-Efficacy to Achieve Competence. Journal of Cognitive Psychotherapy: An International Quarterly, 27, p. 71-80. Retrieved from http://www.ingentaconnect.com.proxy.library.vcu.edu/content/springer/jcogp/2013/

Behavioral Risk Factor Surveillance System, Retrieved from www.vdh.virginia.gov/ohs/brfss

Carnethon, M. C. (2008). Diabetes prevention in U.S ethnic minorities: Role of the social environment. Journal of the American Dietetic Association, 108, 942-944. Retrieved fromhttp://www.sciencedirect.com.proxy.library.vcu.edu/science/article/pii/S0002822308 0032833

Centers for disease control (2003). National diabetes fact sheet, Retrieved from http://www.cdc.gov/diabetes/pbs/

Centers for disease control (2008). National diabetes fact sheet, Retrieved from http://www.cdc.gov/nchs/data/nhsr/nhsr025.pdf-

Centers for disease control (2011). National diabetes fact sheet, Retrieved from http://www.cdc.gov/diabetes/pbs/

Centers for disease control (2013). National diabetes fact sheet, Retrieved from http://www.cdc.gov/diabetes/pbs/ 
Chow, E., Foster, H., Gonzalez, V., \& Melver, L. (2012). The disparate impact of diabetes on racial/ethnic minority populations. Clinical Diabetes Journal, 30, 130-133. Retrieved from http://www.clinical.diabetesjournals.org

Cowie, C., \& Ederhardt, M. (1995). Socioedemographic characteristics of persons with diabetes. National Institutes of Health, 95(1468), 85-116. Retrieved from http://web.ebscohost.com.proxy.library.vcu.edi/ehost

COACH program,(1995). Retrieved from http://thecoachprogram.com

Diabetes statistics. (2011). Retrieved from http://www.diabetes.org/diabetes-statistics Diabetes and its awful toll quietly emerge as a crisis.

Evans, M. (2007). Evidence-based practice protocol to improve glucose control in individual with type 2 diabetes mellitus. The Journal for Nurse Practitioners, 9, 416-422. Retrieved from http://www.npjournal.org

Flegal, K. M., Tabak, C. J., \& Ogden, C.L. (2006). Overweight in children: Definitions and interpretation. Health Education Research, 21, 755-760. Retrieved from http://her.oxfordjournals.org.proxy.library.vcu.edu/content/21/6/755

Gamble V. (2003). A legacy of distrust: African-Americans and medical research. Retrieved from American Journal of Preventive Medicine, p. 35-38.

Horrowitz, C.R., Colson, K.A., Herbert, P.L., \& Lancaster, K. (2004). Barriers to buying healthy foods for people with diabetes: Evidence of environmental disparities. American Journal of Public Health, 94, 1549-1554. Retrieved from http://www.Americanjournalofpublichealth

Iceland, J., \& Wilkes, R. (2006). Does socioeconomic status matter? Race, class, and residential segregation. Social Problems, 53(2), 248-273. Retrieved from http://www.jstor.org/stable/10.1525/sp.2006.53.2.248 
Kirkman, M., Weinberger, M., Landsman, P., Samsa, G., Shorliffe, E., Simel, D., \& Feussner, J. (1994). A telephone-delivered intervention for patients with type 2 diabtes: Effect on coronary risk factors. Diabetes Care, 17, 840-846. Retrieved from http://www.sciencedirect.com.proxy.library.vcu.edu/science/article/pii/S0002822330718

MacLean, L., White, J., Broughton, S., Robinson, J., Shultz, J., Wilson, M., \& Weeks, D. (2012). Telephone coaching to improve diabetes self-management for rural residents. Clinical Diabetes, 30, 13-16. Retrieved from http://clinical.diabetesjournals.org/

McKenzie, E., \& Shelley, A. (2010). Analysis of the psychosocial impact of a vascular risk factor interventions: Results from a cluster randomized controlled trial in Australian general practice. American Journal of Public Health, 36, 45-52. Retrieved from http://www.ncbi.nlm.nih.gov

Merriam Webster dictionary(2014) Retrieved from Www.merriam-webster.com

Monsivais, P., \& Drewnowski, A. (2007). The rising cost of low-energy-density foods. Journal of American Dietetic Association, 107, 2071-2076.Retrieved from http://www.sciencedirect.com.proxy.library.vcu.edu/science/article/pii/S0002822307018 $\underline{007}$

National Health and Nutrition Examination Survey 2009-2010, Retrieved from www.cdc.gov/nchs/nhanes/search/nhanes09-10.aspx

Novo Nordisk Inc. 2015, Retrieved from www.cornerstones4care.com

Odnoletkova, E. A. (2014). Nurse-lead telecoaching of people with type 2 diabetes in primary care: Rationale, design and baseline data of a randomized controlled trial. BioMed Central, 15(24), 1-9. doi: 10.1186/1471-2296-15-24. Retrieved from http://www.cdc.gov/nchs/data/databriefs/db83.pdf 
Ogden, C., Carroll, M., Kit, B., \& Flegal, K. (2012). Prevalence of obesity in the United States. National Health Statistics Reports, 2009-2010. Retrieved from http://www.cdc.gov/nchs/data/databriefs/db82.pdf

Ogden, C. L. and Flegal, K. M. (2010). Changes in Terminology for Childhood Overweight and Obesity. National Health Statistics Reports, 25, 1-6. Retrieved from http://www.cdc.gov/nchs/data/nhsr/nhsr025.pdf

Osborn, C., Cavanaugh, K., Wallison, K., \& Rothman, R. (2010). Self-efficacy links to health literacy and numeracy to glycemic control . Journal of Health Community, 15, 146-158. Retrieved from http://her.oxfordjournals.org.proxy.library.vcu.edu/content21/7/756

Oxford English dictionary 2010. Retrieved from Www.oxforddictionaries.com

Prochaska, J., \& DiClemente, C. (1992). Progress in behavior modification. National Health Statistics Reports, 28, 183-218. Retrieved from http://www.cdc.gov/nchs/data/nhsr/nhrs024.pdf

Ryn, M., \& Fu, S. (2003). Paved with good intentions: Do public health and human service providers contribute to racial/ethnic disparities in health? American Journal of Public Health, 93(2), 248-255. Retrieved from http://www.ncbi.nlm.nih.gov/pmc/articles

Schulze, M. B., \& Hu, F. B. (2005). Primary prevention of diabetes: What can be done and how much can be prevented? Annual Review of Public Health, 26, 445-467. Retrieved from http://www.cdc.gov/nchs/data/nhsr/nhrs024.pdf

The COACH program. (1995). Retrieved from http://thecoachprogram.com

United States Census Bureau, American Community Survey 2009, Retrieved from U.S. Census Bureau (2009). http//quickfactscensus.gov/states/51/5195.html United States Department of Agricultural 2010, Retrieved from 
www.usda.gov/wps/portal/usda/usdahome

Valliantos, Shafter and Gottlieb "Transportation and food: The importance of Access" Los Angeles CA: Center for Food and Justice, Urban and Environmental policy institute, 2002. Retrieved from http://www.uepi.oxy.edu

Virginia Department of Health (2010). Diabetes in Virginia. Richmond VA: VDH, Division of Prevention and Health Promotion, Retrieved from https://www.vdh.virginia.gov/ofhs/prevention/diabetes/documents/2010/pdf/diabetes

Wang, Y., Gortmaker, S., Sobol, S., \& Kuntz, A. (2006). Quantification of the effect of energy imbalance on bodyweight. The Lancet, 378(9793), 826-837. Retrieved from http://www.thelancet.com/journals/lancet

World Health Organization (2012), Retrieved from http://www.who.int/diabetes/actionw/en/DANbooklet.pdf

White, R., Beech, B., \& Miller, S. (2009). Health care disparities and diabetes care: Practical considerations for primary care providers. British Medical Journal, 27(3), 105-112. Retrieved from http://www.clinical.diabetesjournals.org

Zhang, Q., Wang, Y. \& Huang, E.S. (2009)._Changes in racial/ethnic disparities in the prevalence of type 2 diabetes by obesity level among US adults. Ethnicity \& Health, 14, 439-457. Retrieved from http://web.ebscohost.com.proxy.library.vcu.edu/ehost/pdfviewer/pdfviewer?vid=16\&sid= d8be5448-6ae5-4c55-a6e6-d017ea766e1c\%40sessionmgr4\&hid=1 


\section{Appendix A}

IRB-HSR \# 17854: Evaluation of a Coaching Program for African Americans with Type 2 Diabetes

\section{STUDY PROCEDURES}

- You will receive a letter welcoming you to the coaching program, and giving you contact information for the person in charge of this study

- We will ask you to participate in 12 coaching telephone calls over the next 6 week period. Phone calls will last about 15 minutes each time.

- Before the telephone sessions start, you will be asked some questions so that we may learn about your knowledge of diabetes. This will take about 15 minutes to complete.

- We will ask you to report a fasting blood sugar value to us. You will not be asked to check any extra blood sugar levels, but we would like to record a blood sugar level that you have taken as part of your self-care.

- You will also receive a folder and calendar. We will ask you to use this folder to keep track of your appointments for telephone calls. You can also use this folder to make notes during the phone calls, and to write down any questions you may wish to ask during the phone calls.

- During the phone calls, we will ask you some questions about your medications, diet, blood sugar levels, and your activity. Please let us know any areas of concern you have about your diabetes, and we will use the remaining time to answer your questions, and to share information about managing diabetes that might be helpful.

- At the end of the six weeks of coaching phone calls, we will ask you to repeat the knowledge quiz for diabetes. We will review the answers to these questions with you.

- We will ask you to report an additional fasting blood sugar level, taken as part of your normal care at home.

- We will also ask you to some questions about the coaching sessions. Please share your honest opinions with us so that we may learn whether this type of care is helpful. This will take about 10 minutes to complete.

- Your study visits are not meant to take the place of any office visits you may need. You will still need to keep any clinic appointments you may have that are part of your medical care.

\section{How long will this study take?}

Your participation in this study will require 12 of study visits over a 6 week period of time. Each visit will last about 15 minutes, thought the first and last visit will be longer because of the questionnaires.

Page 2 of 7

Version Date: 01/15/15 
IRB-HSR \# 17854: Evaluation of a Coaching Program for African Americans with Type 2 Diabetes

All of your study visits will be completed by telephone.

If you want to know about the results before the study is done:

During the study your study leader will let you know of any information that may be important to your health. In addition, as the research moves forward, your study leader will keep you informed of any new findings that may be important for your health or may help you decide if you want to continue in the study. The final results of the research will not be known until all the information from everyone is combined and reviewed. At that time you can ask for more information about the study results.

\section{Other unexpected risks:}

You may have side effects that we do not expect or know to watch for now. Call the study leader if you have any symptoms or problems.

\section{Could you be helped by being in this study?}

You may or may not benefit from being in this study. Possible benefits include learning more about how to manage your diabetes. In addition, information researchers get from this study may help others in the future.

\section{What are the risks of being in this study?}

Someone might see your private information.

\section{What are your other choices if you do not join this study?}

You do not have to be in this study to be treated for your illness or condition. You can get the usual treatment even if you choose not to be in this study. The usual treatment would include continuing to manage your diabetes without the coaching telephone calls.

If you are an employee of UVa your job will not be affected if you decide not to participate in this study.

If you are a student at UVa, your grades will not be affected if you decide not to participate in this study.

\section{Will you be paid for being in this study?}

You will not get any money for being in this study.

\section{Will being in this study cost you any money?}

All of the procedures in this study will be provided at no cost to you or your health insurance. 
IRB-HSR \# 17854: Evaluation of a Coaching Program for African Americans with Type 2 Diabetes

\section{What if you are hurt in this study?}

If you are hurt as a result of being in this study, there are no plans to pay you for medical expenses, lost wages, disability, or discomfort. The charges for any medical treatment you receive will be billed to your insurance. You will be responsible for any amount your insurance does not cover. You do not give up any legal rights, such as seeking compensation for injury, by signing this form.

\section{What happens if you leave the study early?}

You can change your mind about being in the study any time. You can agree to be in the study now and change your mind later. If you decide to stop, please tell us right away. You do not have to be in this study to get services you can normally get at the University of Virginia.

Even if you do not change your mind, the study leader can take you out of the study. Some of the reasons for doing so may include

a) Your study team member is concerned about your health

b) You do not follow instructions

c) The study sponsor closes the study for safety, administrative or other reasons

If you decide to stop being in the study, we will ask you to tell the study team right away.

\section{How will your personal information be shared?}

The UVa researchers are asking for your permission to gather, use and share information about you for this study. If you decide not to give your permission, you cannot be in this study, but you can continue to receive regular medical care at UVA.

\section{If you sign this form, we may collect any or all of the following information} about you:

- Personal information such as name, address and date of birth

- Social Security number ONLY IF you are being paid to be in this study

- Your health information if required for this study. This may include a review of your medical records and test results from before, during and after the study from any of your doctors or health care providers. This may include mental health care records, substance abuse records, and/or HIV/AIDS records.

\section{Who will see your private information?}

- The researchers to make sure they can conduct the study the right way, observe the effects of the study and understand its results

- People or groups that oversee the study to make sure it is done correctly

- The sponsor(s) of this study, and the people or groups it hires to help perform or review this research

Page 4 of 7

Version Date: 01/15/15 
IRB-HSR \# 17854: Evaluation of a Coaching Program for African Americans with Type 2 Diabetes

- Insurance companies or other organizations that may need the information in order to pay your medical bills or other costs of your participation in the study

- Tax reporting offices (if you are paid for being in the study)

- People who evaluate study results, which can include sponsors and other companies that make the drug or device being studied, researchers at other sites conducting the same study, and government agencies that provide oversight such as the Food and Drug Administration (FDA) if the study is regulated by the FDA.

Some of the people outside of UVa who will see your information may not have to follow the same privacy laws that we follow. They may release your information to others, and it may no longer be protected by those laws.

The information collected from you might be published in a medical journal. This would be done in a way that protects your privacy. No one will be able to find out from the article that you were in the study.

A description of this clinical trial will be available on $h t t p: / /$ www.ClinicalTrials.gov, as required by U.S. Law. This Web site will not include information that can identify you. At most, the Web site will include a summary of the results. You can search this Web site at any time.

\section{What if you sign the form but then decide you don't want your private information shared?}

You can change your mind at any time. Your permission does not end unless you cancel it. To cancel it, please send a letter to the researchers listed on this form. Then you will no longer be in the study. The researchers will still use information about you that was collected before you ended your participation.

\section{Please contact the researchers listed below to:}

- Obtain more information about the study

- Ask a question about the study procedures or treatments

- Report an illness, injury, or other problem (you may also need to tell your regular doctors)

- Leave the study before it is finished

- Express a concern about the study

Principal Investigator: Kathryn Reid

University of Virginia School of Nursing

225 Jeanette Lancaster Way

Charlottesville, VA 22903-3388

Telephone: (434)924-0115

Page 5 of 7

Version Date: 01/15/15 
IRB-HSR \# 17854: Evaluation of a Coaching Program for African Americans with Type 2 Diabetes

\section{What if you have a concern about this study?}

You may also report a concern about this study or ask questions about your rights as a research subject by contacting the Institutional Review Board listed below.

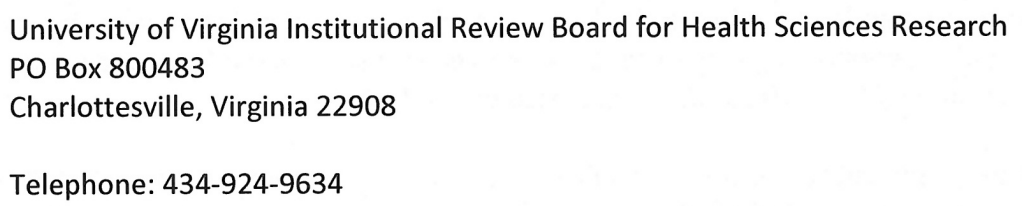

When you call or write about a concern, please give as much information as you can. Include the name of the study leader, the IRB-HSR Number (at the top of this form), and details about the problem. This will help officials look into your concern. When reporting a concern, you do not have to give your name.

\section{Signatures}

What does your signature mean?

Before you sign this form, please ask questions about any part of this study that is not clear to you. Your signature below means that you have received this information and all your questions have been answered. If you sign the form it means that you agree to join the study. You will receive a copy of this signed document.

\section{Consent From Adult}

PARTICIPANT

(SIGNATURE)

To be completed by participant if 18 years of age or older.

(PRINT)

$\overline{\text { PARTICIPANT }} \overline{\text { DATE }}$

PERSON OBTAINING CONSENT

DATE

(SIGNATURE)

(PRINT)

Consent from Impartial Witness

If this consent form is read to the subject because the subject is blind or illiterate, an impartial witness not affiliated with the research or study doctor must be present for the

Page 6 of 7

Version Date: 01/15/15 
IRB-HSR \# 17854: Evaluation of a Coaching Program for African Americans with Type 2 Diabetes

consenting process and sign the following statement. The subject may place an $X$ on the Participant Signature line above.

I agree the information in this informed consent form was presented orally in my presence to the identified individual(s) who has had the opportunity to ask any questions he/she had about the study. I also agree that the identified individual(s) freely gave their informed consent to participate in this trial.

IMPARTIAL WITNESS

IMPARTIAL WITNESS

DATE

(SIGNATURE)

(PRINT)

Page 7 of 7

Version Date: 01/15/15 
Appendix B

Dear participants,

\section{Welcome Letter}

Welcome and thank you for choosing to participate in the six weeks COACH program. The $\mathrm{COACH}$ program uses structured telephone coaching of patients and this approach encourages the patient to self- manage by making relevant behavior changes thus empowering patients to take a greater role in a therapeutic partnership with their health care providers. The COACH program will last for six weeks and each participant will be called twice per week at a mutual time that has been established between the $\mathrm{COACH}$ and the participants. There is a checklist that will be utilized to guide the conversation and a pre and post- test questionnaire will be administered along with fasting blood sugars prior to and at the conclusion of the six weeks $\mathrm{COACH}$ program.. If at any time you have questions please do not hesitate to contact Dianna B White FNP-BC at Norfolk Community Health Center 757-623-0095.

Sincerely

Dianna B White FNP-BC 
Appendix C

Demographic questionnaire

\begin{tabular}{|ll|l|l|l|l|l}
\hline $\begin{array}{l}\text { Year diagnosed } \\
\text { with type 2 DM }\end{array}$ & Age & Education & Income & $\begin{array}{l}\text { Year } \\
\text { attended } \\
\text { diabetes } \\
\text { education } \\
\text { class }\end{array}$ & \\
\hline$\# 1 . \quad 2009$ & 77 & High School & Retired & 2009 & Address \\
\hline$\# 2 . \quad 2007$ & 48 & College Grad & $\$ 43,000$ & 2007 & XXXXXXXXX \\
\hline$\# 6 . \quad 2000$ & 87 & High School & Retired & 2000 & XXXXXXXXX \\
\hline$\# 7 . \quad 2005$ & 69 & High School & $\$ 50,000$ & 2005 & XXXXXXXXX \\
\hline$\# 8 . \quad 2006$ & & High School & Retired & 2006 & XXXXXXXXX \\
\hline$\# 9 . \quad 2002$ & & & & & \\
\hline$\# 10 . \quad 2010$ & 61 & College Grad & $\$ 55,000$ & 2010 & XXXXXXXXX \\
\hline
\end{tabular}


Appendix D

Road to Health Pre and Post Test

Pre-test

Post-test

8. The majority people in my family and community will probably get type 2 diabetes

during their lifetime.

Somewhat agree

Strongly agree

Undecided

Strongly disagree

Somewhat disagree

9. If you develop type 2 diabetes, there is none-thing that can be done to prevent type 2 diabetes from worsening?

f. Somewhat agree

g. Strongly agree

h. Undecided

i. Strongly disagree

j. Somewhat disagree

10. None-thing can be done to prevent you from developing type 2 diabetes.

f. Somewhat agree

g. Strongly agree

h. Undecided

i. Strongly disagree

j. Somewhat disagree 
11. Because there are numerous recommendations about healthy ways to eat; it's impossible to know what to believe.

f. Somewhat agree

g. Strongly agree

h. Undecided

i. Strongly disagree

j. Somewhat disagree

12. What are some of the risk factors for developing type 2 diabetes?

Being overweight /obese

Being over the age of 55

Gestational diabetes (having diabetes when you are pregnant )

Engaging in a sedentary lifestyle (lack of exercise)

d. None of the above

e. Don't' know

f. All of the above

13. Type 2 diabetes

Can lead to heart attack and strokes

Can develop at any age

Can potentially cause problems with the eyes, kidneys and feet More common in older adults

d. None of the above

e. Don't' know

f. All of the above 
14. It's hard for my family to get fresh fruits and vegetables.
a. Somewhat agree
b. Strongly agree
c. Undecided
d. Strongly disagree
e. Somewhat disagree

8. What a person eats makes a big difference in his or her chances of developing type 2 diabetes.
a. Somewhat agree
b. Strongly agree
c. Undecided
d. Strongly disagree
e. Somewhat disagree

9. Exercise or physical activity does affect whether a person develops type 2 diabetes.
a. Somewhat agree
b. Strongly agree
c. Undecided
d. Strongly disagree
e. Somewhat disagree

10. If diabetes runs in a person's family

The person is at increased risk of developing diabetes The person should modify diet and increase exercise
a. None of the above
b. All of the above 
c. Don't' know

11. Identify which of the following foods you think are high in fat:

_ White bread
_ Bananas
_ Macaroni and cheese
Creamed corn

\begin{tabular}{|c|c|}
\hline Crackers & French fries \\
\hline Hamburger & Butter \\
\hline Bologna & Mayonnaise \\
\hline Frozen pizza & Hot dog \\
\hline
\end{tabular}

Identify which of the following foods you think are high in fat:

$\begin{array}{lll}\text { _ White bread } & \text { Crackers } & \text { French fries } \\ \text { Bananas } & \text { Hamburger } & \text { Butter } \\ \text { Macaroni and cheese } & \ldots \text { Bologna } & \text { Mayonnaise } \\ \text { Creamed corn } & \ldots \text { Frozen pizza } & \text { _ Hot dog }\end{array}$


Appendix E

Pre-and Post Fasting blood sugars values

\begin{tabular}{|l|l|l|}
\hline Participants & $\begin{array}{l}\text { Pre-Fasting Blood Sugars } \\
\text { January } 29^{\text {th }}, 2015\end{array}$ & $\begin{array}{l}\text { Post Fasting Blood Sugars } \\
\text { March } 2^{\text {nd }}, 2015\end{array}$ \\
\hline$\# 1$. & & \\
\hline$\# 2$. & & \\
\hline$\# 3$. & & \\
\hline$\# 4$. & & \\
\hline$\# 5$. & & \\
\hline$\# 6$. & & \\
\hline$\# 7$. & & \\
\hline$\# 8$. & & \\
\hline$\# 9$. & & \\
\hline$\# 10$. & & \\
\hline
\end{tabular}


Appendix F

$$
\text { Telephone checklist }
$$

The following questions will be covered in the 15 minute bi-weekly telephone sessions:

9. How is everything going with type 2 diabetes?

10. Are you taking medications for type 2 diabetes mellitus?

11. If yes, what medications and how often?

12. What did your diet consist of over the last 24 hours?

13. Are you self-monitoring your fasting blood glucose levels at home?

14. If yes how often?

15. What were your blood glucose values over the last 24 hours?

16. Are you getting exercise of moderate intensity at least three times a week for 30 minutes at a time? 
Appendix G

Diabetes telephone COACH program Evaluation Form

6. What did you like about the $\mathrm{COACH}$ program?

7. What did you not enjoy about the telephone $\mathrm{COACH}$ program?

8. Would you recommend the telephone $\mathrm{COACH}$ program to friends and family?

9. Was the $\mathrm{COACH}$ friendly?

10. Will you continue the modified diet and exercise implemented during the $\mathrm{COACH}$ program? 


\section{Appendix H}

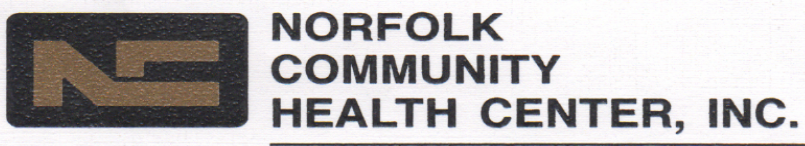

1401 Tidewater Drive, Suite 1 - Norfolk, Virginia 23504 (757) 623-0095 - Fax (757) 623-1203

November 16, 2014

Attention: University of Virginia

Institutional Review Board

Re: Dianna Beale White's Project on Evaluating the COACH Program for African Americans with Type 2 Diabetes

This letter serves to verify that the request by Dianna Beale White to conduct the project on evaluating the COACH Program for African Americans with Type 2 Diabetes at the Norfolk Community Health Center is approved.

Please contact me should you need any further information, I can be reached at 757-692-0205

Sincerely

Dr. Angela M. Mercer

Medical Director 
Appendix I

Instructions for Authors

Clinical Diabetes Journal
Clinical Diabetes Instructions for Authors Updated on 19 November 2012.

How do I submit a paper to the journal? About the Journal Editorial Office Contact Info Manuscript Types Manuscript Format Manuscript

Style Requirements Accepted Manuscripts

\section{HOW DO I SUBMIT A PAPER TO THE JOURNAL?}

Please read the complete instructions for authors before submitting your manuscript to Clinical Diabetes. Manuscripts may be submitted via http://mc.manuscriptcentral.com:80/clinical-diabetes.

ABOUT THE JOURNAL The mission of Clinical Diabetes is to provide primary care providers and all clinicians involved in the care of people with diabetes with information on advances and state-of-the-art care for people with diabetes. Clinical Diabetes is also a forum for discussing diabetes-related problems in practice, medical-legal issues, case studies, digests of recent research, and patient education materials.

All submissions to Clinical Diabetes will be reviewed by the editorial team and considered for publication if they contain information that would be helpful to the journal's readership. All articles, whether invited and submitted, should be written with General Practice, Family Practice or Internal Practice Physicians in mind as the main audience.

Clinical Diabetes adheres to the recommendations of the Council of Science Editors as they relate to editorial review procedures and policies, publication procedures and policies, and roles, responsibilities, and rights of editors. Comprehensive information related to the editorial and ethical policies of Clinical Diabetes can be found in Publication Policies and Prodecures.

Clinical Diabetes subscribes to the requirements stated in the Uniform Requirements for Manuscripts (URM) Submitted to Biomedical Journals. Please refer to these requirements when submitting your manuscript.

EDITORIAL OFFICE CONTACT INFORMATION Davida F. Kruger, MSN, APRN-BC, BC-ADM, the editor-in-chief of Clinical Diabetes, began her term with the Winter 2011 issue. Manuscripts should be submitted to 
http://mc.manuscriptcentral.com/clinical-diabetes. Please read the following instructions before submitting your manuscript. Once you have submitted your manuscript, the review process takes between 4 and 6 weeks. Failure to follow the submission instructions may delay the review process.

Editor-in-Chief: Davida F. Kruger, MSN, APRN-BC, BC-ADM Henry Ford Medical Center - NCO Division of Endocrinology, Diabetes, Bone and Mineral Disease. Detroit, Michigan E-mail: dkruger1@hfhs.org

Deputy Editor: Virginia Valentine, CNS, BC-ADM, CDE Diabetes Network, Inc. Albuquerque, New Mexico E-mail:vv@diabetestalk.com

Deputy Editor: John Raymond White, Jr., PA-C, Pharm.D Department of Pharmacotherapy Washington State University Spokane Spokane, Washington E-mail: whitej@wsu.edu

Associate Editor: Arti Bhan, MD Department of Endocrinology Henry Ford Health System Detroit, Michigan E-mail: abhan2@hfhs.org

Associate Editor: John E. Brunner, MD Endocrine \& Diabetes Care Center Toledo, Ohio E-mail: endojack@aol.com

Associate Editor: Stephen Brunton, MD Cabarrus Family Medicine Residency Program Charlotte, North Carolina E-mail: ozdoc@aol.com

Associate Editor: Robert J. Chilton, MD Department of Cardiology University of Texas Health Science Center at San Antonio San Antonio, Texas Email: chiltonr@gmail.com

Associate Editor: Joseph Largay, PAC, CDE Univ. of North Carolina Diabetes Care Center Durham, North Carolina E-mail: jlargay@med.unc.edu

Associate Editor: Gayle M. Lorenzi, RN, CDE University of California at San Diego La Jolla, California E-mail: glorenzi@ucsd.edu

Associate Editor: Melinda Downie Maryniuk, MEd, RD, CDE, FADA Joslin Diabetes Center Boston, Massachusetts E-mail:

melinda.maryniuk@joslin.harvard.edu

Associate Editor: Heather Remtema, MPH, RD, CCRP Department of Endocrinology Henry Ford Health System Detroit, Michigan E-mail: hremtem1@hfhs.org 
MANUSCRIPT TYPES Clinical Diabetes offers long feature articles, which can present either original research or reviews of the literature on a given topic in clinical diabetes care. The journal also includes several standing departments, which offer shorter articles focused on well-defined topic areas. Guidelines for each type of articles are included in separate sections below.

Feature Articles Feature articles on topics related to diabetes in primary practice are published in each issue of Clinical Diabetes. If the article is an invited feature, members of the editorial team will discuss content with invited authors at the time the invitation is extended. Each feature article should be $3000-5000$ words long, including references. The word count for articles that contain tables, figures, or other illustrations should be adjusted down by approximately 500 words for every half-page table, figure, or illustration. (Example: if an author is planning to include two half-page tables, the total word count on the article text (not counting the tables) should be 2000-4000 to ensure enough room for the tables.

Feature articles should follow the general guidelines set forth in this document. Authors should include a very brief (2-3 sentence) summary of the article, which will appear on the first page of the printed article in lieu of a traditional abstract. Samples articles are available on the journal website.

Guest Editorials Guest editorials should be opinion articles of approximately 800 words in length. The articles should follow the general guidelines set forth in this document. Sample articles are available on the journal website.

"Translating Research to Practice" Articles Articles written for the "Translating Research to Practice" department offer summaries and discussions of current research studies related to diabetes clinical care. Each article should be approximately 1600 words long and should follow the general guidelines set forth in this document. "Translating Research to Practice" articles should be structured in the following format:

G. Title of your article

$\mathrm{H}$. $\quad$ Citation for the research study on which you are writing, including all author names, full title of the research article, journal of publication, volume, page range, and year of publication

I. Reviewed by (your name)

J.Summary of the research article, including brief descriptions of the study objective, design, subjects, methods, results, and conclusion

K. Discussion of the significance of this research, including its applicability to clinical diabetes care, especially in the primary practice setting

L.References

Sample articles are available on the journal website. 
"Practical Pointers" Articles "Practical Pointers" articles offer a discussion of the basics of some aspect of diabetes care. These articles should be 2400-4000 words long and should follow the general guidelines set forth in this document. When appropriate, these articles are accompanied by a patient information page ( 300-400 words at approx. 4th-6th -grade reading level), written for patients, which our readers can photocopy and hand out in their practices. Information pages are written either by the article author, journal staff, or, if time allows, by a free-lance medical and science writer hired by Clinical Diabetes. Sample articles are available on the journal website.

"Case Studies" Articles Articles written for the "Case Studies" department present real patient cases from the authors' practices illustrating specific points in the care of diabetes patients. Each article should be 800-1600 words and should follow the general guidelines set forth in this document. "Case Studies" articles should be structured in the following format:

H. Case study title

I. Your name

J. Brief case presentation, including symptoms at presentation, significant history, physical exam, and lab results

K. Questions raised by this case

L. Commentary

M. Summary of the "clinical pearls" exemplified by this case

N. A brief list of references or suggested readings

Sample articles are available on the journal website.

"Bridges to Excellence" Articles Articles for this department focus on quality improvement initiatives. Submitted articles should provide brief vignettes describing a clinic's or institution's efforts to improve diabetes care. Any attempts to improve the health or health care of people with diabetes, regardless of their outcomes, are welcome. Articles should be 800-1,200 words. Sample articles are available on the journal website.

\section{MANUSCRIPT FORMAT}

Title Page Every manuscript must have an accompanying title page. The title page should include the title; the first name, middle initial, last name, and the highest academic degree of each author; affiliation (in English) of each author; and name, current address, telephone number, fax number, and e-mail address of the corresponding author.

All text and tables should be saved in Word document format. Doing so will allow our Editorial Office to verify the word count and our production staff to turn your 
paper (if accepted) into an article.

Please do not use headers, footers, or endnotes in your paper.

Acknowledgments The acknowledgments should go after the main text and before the reference list. Acknowledgments should contain brief statements of assistance, financial support, and prior publication of the study in abstract form, where applicable.

References The reference list should go at the end of the document, after the main text and acknowledgments (if applicable) and before the tables. References should be numbered in the order that they are cited in the text.

Reference numbers in the text should be in normal type and in parentheses [e.g., "In the study by Norton et al. (23)..."]. Please do not use the footnote/endnote functions found in some word processing programs.

See below for examples of how to style each reference in the reference list.

Tables Tables should be double spaced on separate pages and included the end of the text document, with the table number and title indicated. Tables should be created using Word and the "Insert Table" command; please do not use tabs and/or spaces to create tables, columns, or rows. Tables with internal divisions (Tables $1 \mathrm{~A}$ and B) should be submitted as individual tables, i.e., Tables 1 and 2. Symbols for units should be confined to column headings. Abbreviations should be kept to a minimum and defined in the table legend. For footnotes, use the following symbols consecutively, left to right, top to bottom of table: *, †, $, \S, \|$, ПI, \#, ${ }^{* *}$, ††, etc.

If tables are taken from other sources, the author must be able to provide written permission for reproduction obtained from the original publisher and author.

Figures Clinical Diabetes uses digital publishing methods throughout the journal production process. If your article is accepted, it will be published both in the printed journal and online. The following sections provide information on how to format your figures to ensure the best possible reproduction of your images.

Size. Figures should be produced at the size they are to appear in the printed journal. Please make sure your figures will fit in one, two, or three columns in width. Multi-paneled figures should be assembled in a layout that leaves the least amount of blank space. 1 column $=13$ picas wide, 2.2 in, $5.6 \mathrm{~cm} 2$ columns $=28$ picas wide, $4.6 \mathrm{in}, 11.7 \mathrm{~cm} 3$ columns $=41$ picas, $6.8 \mathrm{in}, 17.3 \mathrm{~cm}$ 
Font. At $100 \%$ size, fonts should be $8-10$ points and used consistently throughout all figures.

Text. Information on the axes should be succinct, using abbreviations where possible, and the label on the y-axis should read vertically, not horizontally. Key information should be placed in any available white space within the figure; if space is not available, the information should be placed in the legend. In general, figures with multiple parts should be marked $A, B, C$, etc., with a description of each panel included in the legend rather than on the figure.

Line and bar graphs. Lines in graphs should be bold enough to be easily read after reduction, as should all symbols used in the figure. Data points are best marked with the following symbols, again assuring that they will be readily distinguishable after reduction: $\bigcirc \square \square \Delta \boldsymbol{\Delta}_{\text {In }}$ the figure legend, please use words rather than the symbols; e.g., "black circles = group 1; white squares = group 2; black bars = blood glucose; white bars = C-peptide." Bars should be black or white only, unless more than two datasets are being presented; additional bars should be drawn with clear bold hatch marks or stripes, not shades of gray.

Line or bar graphs or flow charts with text should be created in black and white, not shades of gray, which are difficult to reproduce in even tones.

Reproductions. If materials (e.g., figures and/or tables) are taken from other sources, the author must be able to provide written permission for reproduction obtained from the original publisher and author. In addition, the source should be cited at the end of the figure legend. For more information, refer to Permissions: Help for Authors.

Figure legends. Figure legends should be clearly numbered and included the very end of your main text document and should not be included on the separate figure/image files. Please use words to describe symbols used in the figure; e.g., "black circles = group 1; white squares = group 2; black bars = blood glucose; white bars = C-peptide."

Formatting digital files for print reproduction. Computer screens, laser printers, and offset presses are significantly different devices. The ability to print your graphics well on a desktop laser printer does not mean the image can be printed successfully, or at all, on an offset press. Use applications capable of creating high-resolution TIFF, EPS, or JPEG files. It is extremely important that the files be saved at the following resolutions.

Halftones include color or grayscale figures containing pictures only, with no text 
or thin lines, and should be saved at $300 \mathrm{dpi}$.

Combination halftones include color or grayscale figures in combination with text and/or thin lines and should be saved at $600 \mathrm{dpi}$.

Line drawings include artwork made of solid black and white, with no tonal (gray) values, and should be saved at $1200 \mathrm{dpi}$.

Color. Color figures must be created using CMYK color only. Any other format will not be accepted.

Electronic submission of illustrations is encouraged; however, laser-printed, camera-ready artwork may be necessary if submitted electronic files fail to meet criteria for print publishing. Hard-copy versions of figures for accepted manuscripts should be computer-generated laser prints on high-quality laser printer paper. Authors may be asked to prepare new figures if those submitted are not suitable for reproduction. Each figure must have a legend that appears in the text and not on the figure.

MANUSCRIPT STYLE Terminology and Style Articles should be written in clear, concise English following the recommendations for scientific writing found in Scientific Style and Format, the Council of Biology Editors (CBE) style manual (6th ed., 1994, Bethesda, MD, Council of Biology Editors). All accepted manuscripts will be edited according to the CBE style manual and The Chicago Manual of Style (15th ed., 2003, Chicago, IL, The University of Chicago Press) by ADA professional publications staff. The authors are responsible for all statements made in their articles or editorials, including any editing changes made by staff.

The designations type 1 diabetes and type 2 diabetes should be used when referring to the two major forms of diabetes. Abbreviations for diabetes, such as T2D for type 2 diabetes, should not be used. The term diabetic should not be used as a noun. Pharmaceutical agents should be listed by generic name.

Abbreviations Abbreviations should be used only when necessary, e.g., for long chemical names (HEPES), procedures (ELISA), or terms used throughout the article. Abbreviate units of measure only when used with numbers. Abbreviations may be used in tables and figures. The CBE style manual contains lists of standard scientific abbreviations.

Units Clinical laboratory values should be in Syst $\tilde{A} " m e$ International (SI) form. Kilocalories should be used rather than kilojoules. Glycated hemoglobin should be expressed as percentage of total and as standard deviation from mean control 
levels.

References References should be listed according to the following examples and should be numbered in the order that they are cited in the text. All authors must be listed and inclusive page numbers provided. Journal titles should be abbreviated as in the National Library of Medicine's List of Journals Indexed for Medline; for unlisted journals, complete journal titles should be provided. Material that is in press may be cited, but copies of such material may be requested. Authors are responsible for the accuracy of the references.

Journal articles: Banting FG, Best C: The internal secretion of the pancreas. $J$ Lab Clin Med 7:251-266, 1922

Abstracts: Seaborn J: Gastrointestinal side-effects of high-fiber diets in diabetic rats (Abstract). Gut 33:A4304, 1992

Books: Allen FM: Studies Concerning Glycosuria and Diabetes. Bradley RF, Krall LP, Eds. Cambridge, MA, Harvard Univ. Press, 1913

Chapters in books: Stauffacher W, Renold AK: Pathophysiology of diabetes mellitus. In Joslin's Diabetes Mellitus. 11th ed. Marble A, White P, Bradley RF, Krall LP, Eds. Philadelphia, Lea \& Febiger, 1971, p. 35-98

Government publications: Fajans SS (Ed.): Diabetes Mellitus. Washington, DC, U.S. Govt. Printing Office, 1976 (DHEW publ. no. NIH 76-854)

Proceedings and symposia: Steel JM: Prepregnancy counseling and the management of the pregnant woman with diabetes. In Proceedings of the 39th Annual Advanced Postgraduate Course, Orlando, FL, 1992. Alexandria, VA, American Diabetes Association, p. 97-98

Online publications: Beta cell function in type 2 diabetes: glucose metabolism and insulin secretion in the normal pancreas [article online], 1999. Available from http://www.amaryl.com/TXT/Clinical_Management/Overview/beta_cell_failure_T XT.html. Accessed 4 May 2000

REQUIREMENTS Copyright Assignment The American Diabetes Association (ADA) holds the copyright on all material appearing in Clinical Diabetes. All authors must check the appropriate boxes and sign themanuscript submission form, which transfers copyright to the ADA in accordance with the Copyright Revision Act of 1976.

ADA's copyright assignment form addresses permission policies related to reuse 
and post-prints. Please see the revised policy below for the statement of provenance and other conditions:

Reuse. Authors are permitted to reuse portions of their ADA-copyrighted work, including tables and figures, in their own work, and to reuse portions or all of their ADA-copyrighted work for educational purposes, without submitting a request to ADA, provided that the proper citation and copyright information is given.

Post-prints. Authors are permitted to submit the final, accepted version of their manuscript to their funding body, such as $\mathrm{NIH}$, or institution for inclusion in their funding body or institution's database, archive, or repository, or to post the final, accepted version on their personal Web site. These manuscripts may be made freely accessible to the public upon acceptance, provided that the following conditions are observed:

3.Post-prints must include the following statement of provenance and, once the final version has been published in the journal, a link to the final published version of the paper on the journal's Web site: "This is an author-created, uncopyedited electronic version of an article accepted for publication in Clinical Diabetes. The American Diabetes Association (ADA), publisher of Clinical Diabetes, is not responsible for any errors or omissions in this version of the manuscript or any version derived from it by third parties. The definitive publisher-authenticated version is available online at http://clinical.diabetesjournals.org."

4. The version of the manuscript deposited or posted must be identical to the final accepted version, with the exception of the addition of the above statement and any changes necessary to correct errors. Authors may make changes to the posted version to correct mistakes or may issue an erratum at any time. However, the final published version of the manuscript may not be deposited, posted, or later substituted for the post-print.

Duality of Interest All authors must read the ADA Policy Statement on Duality of Interest provided to them by the editorial team and check the appropriate box on the manuscript submission form. Any author who has duality of interest to disclose must attach an additional statement that explains the nature of the duality or conflict of interest. Relevant duality or conflict of interest (or lack thereof) should also be disclosed in the authors' comments to the editor during the submission process.

ACCEPTED MANUSCRIPTS Accepted manuscripts will be scheduled for publication as soon as possible. Correspondence concerning the copyediting and production of accepted manuscripts should be e-mailed to Debbie Fentress, Managing Editor, Clinical Diabetes, at debbiekendall@verizon.net. 
Once an article is submitted, it will be substantively reviewed by the editorial team. A member of the editorial team will contact you if substantive revisions are necessary. Otherwise, your paper will then be forwarded to Clinical Diabetes staff for copyediting for style, grammar, and clarity. The copyedited article will be faxed to you with any final author queries for your final revision and/or approval of the manuscript. Typesetting and page design occur after your final approval. Authors do not review galley proofs. 


\section{American Diabetes Association | Manuscript Submission Form}

Please complete this form and upload it with your submission. Questions regarding this form or its contents should be sent to the Editorial Office at EditorialOffice@diabetes.org.

Manuscript \#:

Title:
Journal:

Author List:

\section{Statement of Originality and Authorship}

We have read and understand the policies and procedures outlined in the journal's online instructions for authors. We approve the submission of this manuscript to the American Diabetes Association (ADA) for publication and have taken due care to ensure the integrity of this work.

We attest that each author has made an important scientific contribution to the study and has assisted with the drafting or revising of the manuscript, in accordance with the definition of an author as stated by the International Committee of Medical Journal Editors (ICMJE) at http://www.icmje.org/recommendations/. The contributions of each individual Author are described in the manuscript.

We confirm that neither the manuscript nor any part of it has been published or is under consideration for publication elsewhere (abstracts excluded). Any reference to or use of previously published material protected by copyright is explicitly acknowledged in the manuscript. Posting of submitted material on a Web site may be considered prior publication and should be noted in the comments to the editor upon submission.

\section{Potential Conflict of Interest Disclosure}

We confirm that potential conflicts of interest for all Authors, or acknowledgment that no conflicts exist, are included in the manuscript's Acknowledgments section. Disclosures include relationships with a company whose products or services are related to the subject matter of the manuscript. Company is defined as a for-profit concern engaged in the development, manufacture, or sale of pharmaceutical or biomedical devices or supplies. Please refer to the "Publications Policies and Procedures" document on the journal's online instructions for authors for examples of relevant duality of interest.

\section{Copyright Assignment Agreement (select one)}

We hereby assign all rights, including but not limited to the copyright, for this manuscript to ADA upon its acceptance for publication. The rights assigned include, but are not limited to, the sole and exclusive rights to license, sell, subsequently assign, derive, distribute, display, and reproduce this manuscript, in whole or in part, in any format, electronic or otherwise, including formats not in existence at the time this agreement was signed. The Authors hereby warrant that they have not granted or assigned, and shall not grant or assign, the aforementioned rights to any other person, firm, organization, or other entity.

Reuse. Authors are permitted to reuse portions of their ADA-copyrighted work, including tables and figures, in their own work, and to reuse portions or all of their ADA-copyrighted work for educational purposes, provided that the proper citation and copyright information is given.

Post-prints. Authors are permitted to submit the final, accepted version of their manuscript to their funding body, such as $\mathrm{NIH}$, or institution for inclusion in their funding body or institution's database, archive, or repository, or to post the final, accepted version on their personal Web site. These manuscripts may be made freely accessible to the public upon acceptance. See the journal's online instructions for authors for more information.

Work Made for Hire

Authorized Representative:

This work was produced for an employer as a "work made for hire." An authorized representative of that employer must sign here to indicate copyright assignment on behalf of the authors. The employer of the author(s) is permitted to transmit the work on an internal, secure network for use by its employees only, provided that such use is for the promotion of its business enterprise and does not imply endorsement by ADA.

\section{Government Employee}

This work was produced by an employee of the United States Government as part of his/her official duties. No copyright exists, and therefore it cannot be transferred.

The Authors agree to the terms outlined in this document and have provided consent to authorize the Corresponding Author to act on behalf of all Authors and enter into this agreement,

Date: 